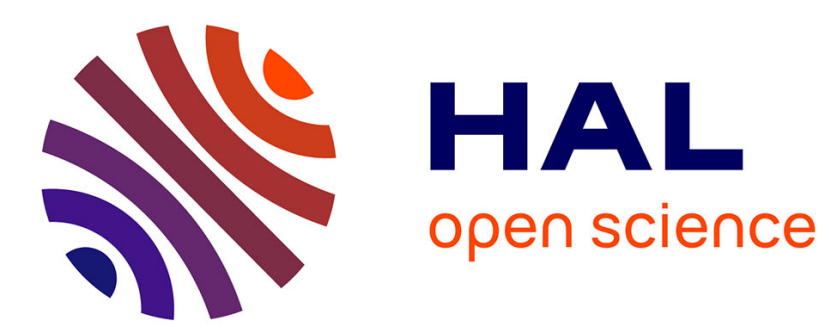

\title{
Modelling Zn (II) sorption onto clayey sediments using a multi-site ion-exchange model
}

E. Tertre, C. Beaucaire, N. Coreau, A. Juery

\section{To cite this version:}

E. Tertre, C. Beaucaire, N. Coreau, A. Juery. Modelling Zn (II) sorption onto clayey sediments using a multi-site ion-exchange model. Applied Geochemistry, 2009, 24, pp.1852-1861. 10.1016/j.apgeochem.2009.06.006 . hal-00450629

\section{HAL Id: hal-00450629 \\ https://hal.science/hal-00450629}

Submitted on 26 Jan 2010

HAL is a multi-disciplinary open access archive for the deposit and dissemination of scientific research documents, whether they are published or not. The documents may come from teaching and research institutions in France or abroad, or from public or private research centers.
L'archive ouverte pluridisciplinaire HAL, est destinée au dépôt et à la diffusion de documents scientifiques de niveau recherche, publiés ou non, émanant des établissements d'enseignement et de recherche français ou étrangers, des laboratoires publics ou privés. 
Modelling Zn (II) sorption onto clayey sediments using a multi-site ion-exchange model

Tertre E. ${ }^{1,2}$, Beaucaire C. ${ }^{1}$, Coreau N. ${ }^{1}$ and Juery A. ${ }^{1}$

${ }^{1}$ CEA Saclay, DEN/DPC/SECR/L3MR, Bat. 450, 91191 Gif sur Yvette, France.

${ }^{2}$ Université de Poitiers, HydrASA FRE 3114 CNRS, 40 avenue du Recteur Pineau, 86022

Poitiers Cedex, France.

*Author to whom correspondence should be addressed:

Emmanuel TERTRE

HydrASA - Bat. Sciences Naturelles

40 Avenue du recteur Pineau

86022Poitiers - France

Email address : emmanuel.tertre@univ-poitiers.fr

Keywords: ion exchange theory, zinc, clayey sediments, geochemical modelling, sorption and desorption experiments. 
Abstract

In environmental studies, we need to be able to predict the behaviour of contaminants in more or less complex physico-chemical contexts. The improvement of this prediction partly depends on establishing thermodynamic models that can describe the behaviour of these contaminants and, in particular, the sorption reactions on mineral surfaces. In this way, based on the mass action law, it is possible to use surface complexation models and ion exchange models. Therefore, the aim of this study is i) to develop an ion-exchange model able to describe the sorption of transition metal onto pure clay minerals and ii) to test the ability of this approach to predict the sorption of these elements onto natural materials containing clay minerals (i.e. soils/sediments) under various chemical conditions.

This study is focused on the behaviour of $\mathrm{Zn}$ (II) in the presence of clayey sediments. Considering that clay minerals are cation exchangers containing multiple sorption sites, it is possible to interpret the sorption of $\mathrm{Zn}(\mathrm{II})$, as well as competitor cations, by ion-exchange equilibria with the clay minerals. This approach is applied with success to interpret the experimental data obtained previously in the $\mathrm{Zn}(\mathrm{II})-\mathrm{H}^{+}-\mathrm{Na}^{+}-$montmorillonite system [Baeyens, B., Bradbury, M.H., 1997. A mechanistic description of Ni and Zn sorption on Namontmorillonite. Part I: Titration and sorption measurements. J. Contam. Hydrol. 27, 199222]. Our research team has already studied the behaviour of $\mathrm{Na}^{+}, \mathrm{K}^{+}, \mathrm{Ca}^{2+}$ and $\mathrm{Mg}^{2+}$ versus $\mathrm{pH}$ in terms of ion exchange onto pure montmorillonite, leading us to develop a thermodynamic database including the exchange site concentrations associated with montmorillonite and the selectivity coefficients of $\mathrm{Na}^{+}, \mathrm{K}^{+}, \mathrm{Ca}^{2+}, \mathrm{Mg}^{2+}$, and $\mathrm{Zn}^{2+}$ versus $\mathrm{H}^{+}$. In the present study, we report experimental isotherms of $\mathrm{Zn}(\mathrm{II})$ on two different sediments in batch reactors at different $\mathrm{pH}$ and ionic strengths, using $\mathrm{NaCl}$ and $\mathrm{CaSO}_{4}$ as electrolytes. Assuming clay minerals are the main ion-exchanging phases, it is possible to predict $\mathrm{Zn}$ (II) sorption onto sediments under different experimental conditions, using the previously obtained data base on montmorillonite. Whatever the physico-chemical conditions tested, we observe a relatively good agreement between experimental results and the predicted sorption behaviour. 
Many models have been proposed in the literature to interpret experimental sorption data obtained with complex mineralogical assemblages, such as sediments and soils (El Aamrani et al., 2002; Kurosawa et al., 2006; Vandenhove et al., 2007). However, these models are often empirical and are not appropriate to cover a wide range of physico-chemical conditions $(\mathrm{pH}$, ionic strength, initial trace element concentration, solid/solution ratio, etc.). This problem is particularly relevant when modelling the sorption of trace elements (i.e. metals) onto solid phases in contact with natural waters in the presence of competitor cations (i.e. $\mathrm{Na}^{+}, \mathrm{K}^{+}, \mathrm{Ca}^{2+}$ and $\mathrm{Mg}^{2+}$ ). In this context, authors commonly use thermodynamic models, based on the mass action law, which simulate the processes of surface complexation and ion exchange.

Surface complexation models require a determination of the surface charge of the solid, the chemical nature of the sorption sites and, ideally, the stoichiometry of the sorbed species. In practice, such information was obtained primarily for simple oxides (goethite, alumina, quartz, calcite, etc.) and, therefore, surface complexation models were widely developed for these pure phases (Benjamin and Leckie, 1981; Davis et al., 1987; Dzombak and Morel, 1990; Zachara et al., 1991; Villalobos and Leckie, 2001; Appelo et al., 2002; Trivedi et al., 2004). For argillaceous minerals, some models were developed combining surface complexation mechanisms with cation exchange reactions (Turner et al., 1996 and 1998; Bradbury and Baeyens, 1997; Poinssot et al., 1999; Tournassat et al., 2004a and b; Tertre et al., 2006a and b). Moreover, the additivity of sorption properties has been validated in some cases, whereby the mineral constituents of a complex assemblage contribute in a linear way to the bulk behaviour, (Davis et al., 2004; Wolthers et al., 2006). However, in certain other examples, the surface complexation approach fails to reproduce environmental situations. This behaviour could be due to the lack of knowledge concerning electrostatic interactions between mineral phases making up a complex material (see discussions in Davis et al., 1998, Davis et al., 2004 and Payne et al., 2004).

Ion exchanger models have also been developed as an alternative to the surface complexation approach, being applied to clay minerals (Ly et al., 1991; Gorgeon, 1994; Nolin, 1997; Motellier et al., 2003; Jacquier et al., 2004) and other phases such as $\alpha$-alumina (Alliot et al., 2005). Although these models are not designed to interpret data on a microscopic scale (surface charge, chemical nature of the sorption sites, etc.), they have the advantage of taking into account the sorption of major and trace elements present in the system. They can be easily integrated in water/rock interaction models containing thermodynamic constants for 
other reactions, such as aqueous complexation and dissolution/precipitation of minerals. The present study is primarily concerned with sorption onto multi-phase solids, which quite naturally leads us to favour the ion exchange approach.

The objective of this study is to develop and test a thermodynamic ion exchange model to interpret the sorption of zinc (i.e. Zn(II)) onto sediments made up of argillaceous minerals. For this purpose, we assume that the minerals controlling the sorption of zinc onto the solid phase are the clay minerals, and in particular montmorillonite. The choice of montmorillonite as a reference clay-mineral to describe $\mathrm{Zn}(\mathrm{II})$ sorption onto soils/sediments is discussed later in section 5 .

Initially, we present the methodology used to build the ion exchange model for $\mathrm{Zn}$ (II) associated with montmorillonite. This is based on experimental sorption data published in the literature and includes sorption reactions of the competitor elements present as major ions. Then, in a second step, we test the validity of our model to interpret experimental data obtained on two different mineralogical assemblages. To achieve this, we compare the experimental sorption data obtained on a soil and a sediment with the predicted sorption calculated by the model built initially for montmorillonite. As detailed in section 5, the models of $\mathrm{Zn}$ (II) sorption onto soil and sediment are based on the data for pure montmorillonite and take into account the cation exchange capacity (i.e. CEC) measured for the complex solids as well as their percentages of montmorillonite. Moreover, some experimental desorption data were obtained on the sediment to check the reversibility of the ion-exchange process, since such a mechanism assumes reversibility.

\section{2- Ion exchanger model}

In this study, we assume that clay minerals (mainly montmorillonite) are the main cation exchangers of the investigated sediment/soil (see section 3). Concerning the other minerals of sediments, such as quartz, Fe-oxyhydroxides and calcite, several studies show that sorption of divalent and trivalent metals onto these minerals is not governed solely by ionexchange/reversible reactions, but more particularly, the formation of solid-solutions 
(carbonates: Davis et al., 1987; Zachara et al., 1991; Tesoriero and Pankow, 1996; Rimstidt et al., 1998; Curti et al., 2005) or inner-sphere complexes by partially reversible sorption (quartz, Fe-oxyhydroxides: Tran et al., 2002; Mustafa et al., 2004; Takahashi et al., 2006; Stumpf et al., 2008).

Formalism of ion exchange

The reader can refer to the detailed formalism presented in Motellier et al. (2003) and Jacquier et al. (2004). Let us consider a negatively charged site $\mathrm{Xi}^{-}$present at the clay mineral surface, which is in equilibrium with an aqueous solution containing only three cations: the proton $\mathrm{H}^{+}$, the cation $\mathrm{Na}^{+}$of the electrolyte (i.e. $\mathrm{NaCl}$ ) and the divalent trace metal $\mathrm{Zn}^{2+}$. The cation exchange reactions between these three ions are described below:

$$
\begin{array}{ll}
\left\{X_{i}^{-} H^{+}\right\}+N a^{+} \leftrightarrow\left\{X_{i}^{-} N a^{+}\right\}+H^{+} & \text {Reaction } 1 \\
2\left\{X_{i}^{-} H^{+}\right\}+Z n^{2+} \leftrightarrow\left\{\left(X_{i}^{-}\right)_{2} Z n^{2+}\right\}+2 H^{+} & \text {Reaction 2 }
\end{array}
$$

The pH-dependence of the cation exchange capacity (i.e. CEC) has already been mentioned (Maes et al., 1976). These authors consider that about 15\% of the total clay charge can be neutralized by protons. Therefore, to interpret ion exchange reactions involving clay minerals, different authors take into account the sorption of protons onto the $\mathrm{X}_{\mathrm{i}}^{-}$sites of clays (Fletcher and Sposito, 1989; Turner et al., 1996; Avena and De Pauli, 1998; Motellier et al., 2003; Tombacz et al., 2004; Jacquier et al., 2004; Tournassat et al., 2004b; Tertre et al., 2006a and b; Gu and Evans, 2007). Following Motellier et al. (2003) and Jacquier et al. (2004), we choose to take the proton as the reference cation, so the equilibrium constants of the two last reactions can be described by equations 1 and 2:

$$
\begin{aligned}
& K_{H / N a}^{i}=\frac{\left[\mathrm{X}_{i}^{-} \mathrm{Na}^{+}\right] \cdot\left[\mathrm{H}^{+}\right] f_{\mathrm{X}_{i}^{-} \mathrm{Na}^{+}} \gamma_{\mathrm{H}^{+}}}{\left[\mathrm{X}_{i}^{-} \mathrm{H}^{+}\right] \cdot\left[\mathrm{Na}^{+}\right] f_{\mathrm{X}_{i}^{-} \mathrm{H}^{+}} \gamma_{\mathrm{Na}^{+}}} \\
& K_{2 H / Z n}^{i}=\frac{\left[\left(X_{i}^{-}\right)_{2} Z^{2+}\right] \cdot\left[H^{+}\right]^{2} \cdot\left(f_{\left(X_{i}^{-}\right)_{2} Z_{n^{2+}}}\right) \cdot\left(\gamma_{H^{+}}\right)^{2}}{\left[X_{i}^{-} H^{+}\right]^{2} \cdot\left[Z^{2+}\right] \cdot\left(f_{X_{i}^{-} H^{+}}\right)^{2} \cdot\left(\gamma_{Z^{2+}}\right)}
\end{aligned}
$$


where $i$ is the number of the considered type of site, [ ] is the concentration of species in solution or sorbed at the solid surface, $f$ and $\gamma$ are the activities of the sorbed and aqueous species, respectively. Since the activity coefficients of the sorbed species are not known, we assume here that the ratio between these coefficients is constant. We then use apparent constants, called selectivity coefficients $\mathrm{K}^{*}$, which are defined according to equations 3 and 4 .

$$
\begin{aligned}
& { }^{*} K_{\mathrm{H} / \mathrm{Na}}^{i}=\frac{\left[\mathrm{X}_{i}^{-} \mathrm{Na}^{+}\right] \cdot\left[\mathrm{H}^{+} y_{H}\right.}{\left[X_{i}^{-} \mathrm{H}^{+}\right] \cdot\left[N a^{+} y_{\mathrm{Na}}\right.} \\
& { }^{*} K_{2 \mathrm{H} / \mathrm{Zn}}^{i}=\frac{\left[\left(X_{i}^{-}\right)_{2} \mathrm{Zn}^{2+}\right] \cdot\left[\mathrm{H}^{+}\right]^{2} \cdot\left(\gamma_{H}\right)^{2}}{\left[X_{i}^{-} H^{+}\right]^{2} \cdot\left[\mathrm{Zn}^{2+}\right]\left(\gamma_{\mathrm{Zn}}\right)}
\end{aligned}
$$

Ion exchange data are obtained for a wide range of ionic strength conditions (i.e. from $10^{-2}$ to $0.5 \mathrm{M})$. Therefore, to use a single activity law, aqueous activity coefficients are calculated with the Davies approximation.

For cations such as transition metals, we must take into account the complexation in solution by $\mathrm{OH}^{-}$and other anions. Therefore, the concentration of the $\mathrm{Zn}^{2+}$ in solution can be expressed as:

$$
\left[\mathrm{Zn}^{2+}\right]=[\mathrm{Zn}(I I)] / \alpha_{\mathrm{Zn}}
$$

where $[\mathrm{Zn}(\mathrm{II})]$ is the total concentration in solution and $\alpha_{\mathrm{Zn}}$ the Ringbom coefficient (Ringbom, 1963), taking into account the aqueous complexation of $\mathrm{Zn}(\mathrm{II})$. This coefficient is calculated from the aqueous complexation constants proposed by Pivovarov (2005).

For each $\mathrm{X}_{\mathrm{i}}^{-}$site, the site concentration $\mathrm{CEC}_{\mathrm{i}}$ is expressed as the sum of the concentrations of the adsorbed cations on the i site:

$$
C E C_{i}=\left[X_{i}^{-} H^{+}\right]+\left[X_{i}^{-} N a^{+}\right]+2 \cdot\left[\left(X_{i}^{-}\right)_{2} Z^{2+}\right]
$$

Combining equations (3), (4), (5) and (6), we obtain the concentration of the sorbed species $\left(X_{i}^{-}\right)_{2} Z^{2+}$ :

$$
\left[\left(X_{i}^{-}\right)_{2} Z n^{2+}\right]=(1 / 8) \cdot\left(4 C E C_{i}+A^{2} \cdot B-\left(A^{4} \cdot B^{2}+8 \cdot C E C_{i} \cdot A^{2} \cdot B\right)^{0.5}\right)
$$


with $A=1+\frac{\left[\mathrm{Na}^{+}\right] \cdot \gamma_{\mathrm{Na}^{+}} \cdot{ }^{*} K_{\mathrm{H} / \mathrm{Na}}^{i}}{\left[\mathrm{H}^{+}\right] \cdot \gamma_{H^{+}}}$and $B=\frac{\left[\mathrm{H}^{+}\right]^{2} \cdot\left(\gamma_{\mathrm{H}^{+}}\right)^{2}}{{ }^{*} K_{2 \mathrm{H} / \mathrm{Zn}}^{i} \cdot\left[\mathrm{Zn}^{2+}\right] \cdot \frac{\gamma_{\mathrm{Zn} n^{2+}}}{\alpha_{\mathrm{Zn}}}}$

$\mathrm{Zn}^{2+}$ can be sorbed on i sites of different nature and, consequently, the total concentration of sorbed $\mathrm{Zn}$ can be written $\left.\overline{\mathrm{Zn}^{2+}}\right]$, which is equal to:

$\left[\overline{\mathrm{Zn}^{2+}}\right]=\sum_{i=1}^{n}\left[\left(X_{i}^{-}\right)_{2} \mathrm{Zn}^{2+}\right]$

For each " $\mathrm{X}_{\mathrm{i}}^{-}$" sorption site of a given pure mineral, we can define two selectivity coefficients: ${ }^{*} K_{H / N a}^{i}$ and ${ }^{*} K_{2 H / Z n}^{i}$.

\subsection{Characterisation of major sites in pure montmorillonite}

The occurrence of multiple types of major sites on a pure mineral is indicated by the sorption behaviour of each major competitor cation present in the studied system. For each of these cations (i.e. $\mathrm{Na}^{+}$in our case), saturation curves can be established by plotting the concentration of the adsorbed cation as a function of $\mathrm{pH}$. In our study, the saturation curves are obtained on conditioned clayey mineral under homo-ionic form (i.e. Na-montmorillonite in our case), and under conditions where major sorption sites can be saturated, i.e. with a slight excess of the cation in solution relative to its possible uptake by the solid (Ly et al., 1991; Gorgeon, 1994; Nolin, 1997; Gaucher, 1998 and Jacquier et al., 2004). As major cations were used, no secondary solid can precipitate even if the concentrations are high (i.e. $\left.\left[\mathrm{Na}^{+}\right]=0.1 \mathrm{~mol} / \mathrm{L}\right)$. Appendix A gives the experimental protocol used by the above authors to obtain experimental data satisfying these conditions.

Gorgeon (1994) and Nolin (1997) used the sorption of $\mathrm{Na}^{+}$to characterize the major sites on the Na-Wyoming montmorillonite. Saturation curves as a function of $\mathrm{pH}$ are interpreted either with a single major site having a concentration of $0.42 \mathrm{~mol} / \mathrm{kg}$ (Gorgeon, 1994), or with three major sites (Nolin, 1997), whose total site concentration $(0.89 \mathrm{~mol} / \mathrm{kg})$ is close to the value classically measured on montmorillonite $\left(\mathrm{CEC}_{\mathrm{TOT}}=0.870 \pm 0.035 \mathrm{~mol} / \mathrm{kg}\right.$ measured by Baeyens and Bradbury, 1997). This difference has been explained by the fact that the montmorillonite used in the first case was not completely saturated with sodium and that 
residual calcium persisted in interlayer spaces. Consequently, we preferred the data obtained by Nolin (1997). Figure 1 shows a comparison between the experimental saturation curve obtained by Nolin (1997) and the best fit with data calculated from the model. Table 1 reports the calculated sorption parameters (i.e. concentration sites and selectivity coefficient ${ }^{*} K_{H / N a}^{i}$ ). To calculate the ${ }^{*} K_{2 H / Z n}^{i}$ selectivity coefficients associated with the three major sites previously characterised by Nolin (1997), we used Baeyens and Bradbury’s experimental data (1997) obtained for the $\mathrm{Zn}(\mathrm{II}) / \mathrm{Na}^{+} / \mathrm{H}^{+}$-montmorillonite system. Indeed, these authors present a whole range of consistent experimental data sets, yielding two sorption isotherms at constant $\mathrm{pH}(\mathrm{pH}=5.6$ and $\mathrm{pH}=7)$ in $0.1 \mathrm{M} \mathrm{NaClO}_{4}$. These experimental isotherms are reported on figures $2 \mathrm{~A}$ and $2 \mathrm{~B}$, in terms of logarithms of the distribution coefficient of zinc as a function of its concentration in solution at equilibrium. According to the results of Nolin (see Table 1), it appears that the sorption isotherms of $\mathrm{Zn}$ (II) cannot be interpreted satisfactorily on the basis of only three major sites (see calculated curves in lines on Figures 2A and 2B).

\subsection{Characterisation of minor sites in pure montmorillonite}

We can clearly see from Fig. 2 that an additional site is required to interpret Kd values obtained at aqueous zinc concentration lower than $10^{-5} \mathrm{~mol} / \mathrm{L}$ at equilibrium. Given the experimental data, this site seems to have a strong affinity for Zn but a very low site concentration. The need to take this type of site into account is frequently mentioned in the literature to interpret sorption isotherms obtained for trace elements, such as caesium and divalent transition metals, which have a strong affinity for clay minerals, (Bradbury and Baeyens, 1997; Poinssot et al., 1999; Steefel et al., 2003; Jacquier et al., 2004; Missana et al., 2004).

A concentration of $5.10^{-3} \mathrm{~mol} / \mathrm{kg}$ was obtained for the low-capacity site, by means of trial and error to achieve a satisfactory fit of the two isotherms. We note that this site accounts for only $0.6 \%$ of the total measured exchange capacity (i.e. $0.88 \mathrm{~mol} / \mathrm{kg}$ ) and, consequently, it cannot be quantifiable in a saturation curve. Table 2 reports the ${ }^{*} K_{2 H / Z n}^{i}$ selectivity coefficients for the 4 sites (3 major sites + site of low capacity), corresponding to the best fit of the experimental sorption isotherms reported by Baeyens and Bradbury (1997). The results of our model are reported in Figs. 3A and 3B, along with the experimental points.

Figures $3 \mathrm{~A}$ and $3 \mathrm{~B}$ show the contribution of each site to the sorption of zinc onto the NaWyoming montmorillonite. Whatever the isotherm modelled, we can clearly see the 
predominance of the site of strong affinity and low capacity (called site "0") when the zinc concentration in solution is lower than $10^{-5} \mathrm{~mol} / \mathrm{L}$. In their surface complexation model, Bradbury and Baeyens also take into account a site of low capacity to fit their experimental data as well as possible. These authors (op cit.) proposed a site of low capacity $\left(2.10^{-3} \mathrm{~mol} / \mathrm{kg}\right.$ ) and strong affinity accounting for $0.2 \%$ of the total measured cation exchange capacity. Their site concentration is in agreement with our estimate. Nevertheless, we note that, on the whole, the nature of this site remains unspecified. Indeed, in terms of crystallography, it cannot be compared to an "aluminol" or a "silanol" site. For a montmorillonite, the density of these sites (“aluminol and silanol sites”), which are still called "edge sites”, is approximately equal to $4 \%$ of the measured total CEC in the case of an aluminol, or $8 \%$ for a silanol (see studies of Avena and De Pauli, 1998; Tombacz et al., 2004).

Finally, we test whether our model is able to reproduce correctly the sorption data obtained by Baeyens and Bradbury (1997) for $\mathrm{Zn}(\mathrm{II})$ at trace concentration as a function of $\mathrm{pH}$, in the same conditions as used for the sorption isotherms (i.e. in $0.1 \mathrm{M} \mathrm{NaClO}_{4}$ solution). With the previously determined parameters given in Table 2, we can see from Fig. 4 that the results of our model predict very well the experimental data obtained by Baeyens and Bradbury (1997). The contribution of each of the four sites (three major sites + site " 0 ”) is clearly apparent on this figure. We note that i) for $\mathrm{pH}<4$, the sorption is interpreted only by considering sites 1 and 2, ii) between $\mathrm{pH} 4$ and 8, the sorption is interpreted by sorption onto sites 1, 2 and 0 and iii) the contribution of site 3 becomes significant only for $\mathrm{pH}>9$.

The model proposed here (see table 2) accounts relatively well for all the experimental data reported by Baeyens and Bradbury (two isotherms and $\mathrm{Kd}$ versus $\mathrm{pH}$ ). In the suggested model, we consider implicitly that only the $\mathrm{Zn}^{2+}$ species is sorbed, whatever the site considered. This is supported by the calculations of aqueous speciation performed with the Phreeqc $2^{\circledR}$ code (Parkhurst and Appelo, 1999) and using the SUPCRT92 data base (Johnson et al., 1992), supplemented by the specific thermodynamic data proposed by Pivovarov (2005) for $\mathrm{Zn(II)} \mathrm{aqueous} \mathrm{species} \mathrm{(see} \mathrm{appendix} \mathrm{B).} \mathrm{In} 0.1 \mathrm{M} \mathrm{NaCl}$ solution having a total carbonate concentration of $10^{-3} \mathrm{~mol} / \mathrm{L}$ (i.e. average value measured in our solutions), and for $\mathrm{pH}$ ranging from 3 to 8 , we find that $\mathrm{Zn}^{2+}$ is the main $\mathrm{Zn}$ (II) aqueous species, whereas, between $\mathrm{pH} 8$ and 9, the dominant aqueous species are $\mathrm{Zn}(\mathrm{OH})_{2 \mathrm{aq}}$ and $\mathrm{ZnCO}_{3 \mathrm{aq}}$. From a total $\mathrm{Zn}$ (II) concentration of $10^{-4} \mathrm{M}$, (to mimic conditions of sorption isotherms at high surface coverage), solutions having $\mathrm{pH}>8$ are saturated with respect to $\mathrm{Zn}(\mathrm{OH})_{2(\mathrm{~s})}$ and $\mathrm{ZnCO}_{3(\mathrm{~s})}$. 
Nevertheless, we assume that, for kinetic reasons, these solids do not precipitate during sorption isotherm experiments when $\mathrm{pH}$ is between 8 and 9. This hypothesis is checked here by sorption-desorption experiments (see desorption results in section 4).

For the sorption of sodium, we should point out that Nolin (1997) mentions only three sites to interpret the saturation curve versus $\mathrm{pH}$. In our study, to interpret all the data of Baeyens and Bradbury (1997), we must take into account the additional site "0" with low capacity and strong affinity. We also check that modelling with an additional site "0" does not affect the previously calculated $\mathrm{Na}^{+}$saturation curve (see figure 1). This behaviour is not surprising since this site corresponds to a maximum of $0.6 \%$ of the total CEC, as already mentioned.

\section{3- Materials and experimental methods}

The main objective of this study is to test the predictive capacity of the ion exchange model proposed above for the zinc/montmorillonite system, to understand and model the sorption behaviour of metal cations (i.e. $\mathrm{Zn}(\mathrm{II})$ ) in the natural environment. In order to validate this model, different experiments were performed in the laboratory to reproduce the sorption behaviour of zinc under physical and chemical conditions representative of natural systems. We worked with two different natural solids: a soil and a sediment.

The soil used in our experiments comes from the Pech Rouge plot (near Montpellier, France), an area already used in previous studies on caesium and strontium migration. Therefore, the characteristics of this solid material are well known, in particular its mineralogy, granulometry and chemistry (see Fernandez et al., 2000 and Beaucaire et al., 2005 and 2006 for more information).

The sediment comes from Auby (Pas-de-Calais, France), corresponding to a deposit that is highly contaminated in transition metals, forming a layer that is sealed off from the underlying aquifer. The contaminated sediments result from the dredging of the river channels. Consequently, the characterisation of the sorption properties of this layer is fundamental to prevent the risks of contamination of the aquifer.

In a first step, we present some physicochemical characteristics of the solids used in the experiments. Then, we describe the protocol of sorption/desorption. 
Materials

Pech Rouge soil

The main characteristics can be found in Fernandez et al. (2000). In the present study, we carried out additional measurements such as qualitative analysis by x-ray diffraction and determination of cation-exchange capacity (see below for the protocol used).

The 80-125 $\mu \mathrm{m}$ granulometric fraction is principally composed of carbonates (18 wt\%), quartz and feldspars (48 wt\%) and clay minerals (34 wt\%). By specific treatments (ethylene glycol and heating), Fernandez et al. (2000) found that clay minerals were composed of about: $62 \mathrm{wt} \%$ illite, $16 \mathrm{wt} \%$ smectite, $12 \mathrm{wt} \%$ kaolinite and $10 \mathrm{wt} \%$ chlorite. The precision of these values is $\pm 5 \%$ The cation-exchange capacity was measured by displacement of major cations (i.e. $\mathrm{Na}^{+}, \mathrm{K}^{+}, \mathrm{Ca}^{2+}$ and $\mathrm{Mg}^{2+}$ ) by $\mathrm{CsCl} 0.05 \mathrm{M}$ at $\mathrm{pH}=8$, yielding an average value of $14.1 \pm 0.4 \mathrm{meq} / 100 \mathrm{~g}$. However, preliminary studies using this method on samples from the same fraction of soil (Beaucaire et al., 2005 and 2006) showed that the heterogeneity is such that the CEC is difficult to estimate with a precision better than $30 \%$.

Auby sediment

This sediment has been largely characterized from a chemical, mineralogical and physical point of view by Lions (2004). The granulometric fraction used in our study is the $<50 \mu \mathrm{m}$ fraction, which is mainly composed of quartz, calcite and clay minerals (mainly smectite and illite/smectite). With the same protocol for measuring the displacement of the exchangeable cations as applied to the used for the soil, we obtained an average measured CEC of $19.9 \pm$ $4.3 \mathrm{meq} / 100 \mathrm{~g}$.

A high zinc content of around $250 \mathrm{ppm}$ has been obtained by acid dissolution $\left(\mathrm{HNO}_{3} / \mathrm{HF}\right)$ of the solid sediment (Lions, 2004). Consequently, before performing sorption experiments, we quantified the labile $\mathrm{Zn}$ concentration by ion-exchange extraction. Therefore, leaching of the sediment was carried out on the fine fraction $(<50 \mu \mathrm{m})$, at $\mathrm{pH} 7.5$ in a $0.05 \mathrm{M} \mathrm{CsCl}$ solution. After one week of leaching, the zinc concentration measured in solution was about $9.10^{-7}$ $\mathrm{mol} / \mathrm{L}$. Taking into account the water/rock ratio used $(30 \mathrm{~g} / \mathrm{L})$, this corresponds to about $4 \%$ of the zinc contained in the solid. Therefore, we assume that $1.5 .10^{-9}$ moles of $\mathrm{Zn}$ are 
quantitatively exchangeable in $1 \mathrm{~g}$ of sediment. This contribution of zinc present initially in the sediment is taken into account in the treatment of the sorption isotherms.

\section{Sorption/desorption experiments}

For the "Pech Rouge" soil, three sorption isotherms at constant $\mathrm{pH}( \pm 0.1)$ were determined using the $80-125 \mu \mathrm{m}$ fraction: one in $0.01 \mathrm{M} \mathrm{NaCl}$, one in $0.5 \mathrm{M} \mathrm{NaCl}$ and one in $0.01 \mathrm{M}$ $\mathrm{CaSO}_{4}$. For the "Auby" sediment, two isotherms were determined with the $<50 \mu \mathrm{m}$ fraction: one in $0.01 \mathrm{M} \mathrm{NaCl}$ and one in $0.01 \mathrm{M} \mathrm{CaSO}_{4}$. The nature and concentration of the electrolyte used were selected to approach contrasted and realistic compositions of natural waters.

The solid fractions were dispersed in a given electrolyte, using a water/rock ratio of $24 \mathrm{~g} / \mathrm{L}$. The suspensions were placed in closed polycarbonate tubes for three days on a shaking bank, at $20^{\circ} \mathrm{C}$. The experiments were carried out without any $\mathrm{CO}_{2}$ control. A known quantity of a zinc stock solution $\left(\mathrm{C}_{\mathrm{Zn}(\mathrm{II})}=3 \cdot 2 \cdot 10^{-3} \mathrm{~mol} / \mathrm{L} ; \mathrm{pH}=2.6\right)$ was then added to each batch. An isotherm was determined at constant $\mathrm{pH}$ in approximately 8 different batches, by increasing the zinc concentration from $10^{-5}$ to $5.10^{-4} \mathrm{~mol} / \mathrm{L}$ before sorption.

After one week of equilibration, the samples were centrifuged at $15000 \mathrm{rpm}$ for $30 \mathrm{~min}$. Depending on the experiment, an aliquot of $100 \mu \mathrm{L}$ to $1 \mathrm{~mL}$ was taken and acidified with $2 \%$ $\mathrm{HNO}_{3}$ for the analysis of zinc in solution by ICP-MS, whereas $2 \mathrm{~mL}$ were taken for $\mathrm{pH}$ measurement. The $\mathrm{pH}$ was measured with a combined Metrohm ${ }^{\circledR}$ electrode calibrated at $20^{\circ} \mathrm{C}$ with three NIST buffer solutions ( $\mathrm{pH}=4.01, \mathrm{pH}=6.98$ and $\mathrm{pH}=9.18)$.

For each isotherm, the $\mathrm{pH}$ variation between the 8 points is less than 0.1 unit $\mathrm{pH}$. The detection limit of ICP-MS analysis of zinc in solution is $1 \mathrm{ppb}$ (i.e. $1.5 .10^{-8} \mathrm{~mol} / \mathrm{L}$ ) and the analytical precision is approximately $5 \%$. To take into account the instability of the apparatus during the analysis, ${ }^{89} \mathrm{Y}$ is used as an internal standard.

The value of the distribution coefficient (i.e. $\mathrm{Kd}_{\mathrm{ads}}$ ), expressed in $\mathrm{L} \mathrm{kg}^{-1}$, is calculated according to the following equation:

$$
K d_{a d s}=\frac{V}{m} * \frac{\left(C_{i}-C_{f 1}\right)}{C_{f 1}}
$$


where $\mathrm{V}$ and $\mathrm{m}$ are, respectively, the volume of the solution (in L) and the mass of the solid (kg), whereas $C_{i}$ and $C_{f 1}$ represent the concentrations of zinc in solution before sorption and at the end of the sorption experiment. Sets of repeat measurements of log Kd indicate an absolute error of $\pm 0.3 \log$ units.

To test the reversibility of the $\mathrm{Zn}(\mathrm{II})$ sorption process, some desorption experiments were performed for the Pech Rouge soil in $0.01 \mathrm{M} \mathrm{NaCl}$. Once the sorption equilibrium was reached, the supernatants were removed and replaced by the same mass of solution, at the same ionic strength and $\mathrm{pH}$, but not containing zinc. After one week of shaking, the protocol used for measuring the distribution coefficient from the desorption stage (denoted $\mathrm{Kd}_{\text {des }}$ ) was the same for the $\mathrm{Kd}_{\mathrm{ads}}$ determination. The expression for $\mathrm{Kd}_{\mathrm{des}}$, measured from the desorption stage, is given below:

$K d_{d e s}=\frac{V}{m} * \frac{\left(C_{i}-C_{f 1}-C_{f 2}\right)}{C_{f 2}}$

In addition to the parameters of equation 9, this expression contains the term $C_{f 2}$ representing the aqueous zinc concentration at the end of the desorption stage.

In the case of the “Auby” sediment, additional sorption measurements were performed using the radioactive isotope ${ }^{65} \mathrm{Zn}$, contained in a stable aqueous $\mathrm{Zn}$ (II) solution having a concentration of $\left[\mathrm{Zn}(\mathrm{II})_{\mathrm{aq}}\right]_{\mathrm{TOT}}=8 \cdot 5 \cdot 10^{-4} \mathrm{~mol} / \mathrm{L}$. This method allows us to investigate the sorption of $\mathrm{Zn}(\mathrm{II})$ at trace concentration (i.e. $<10^{-7} \mathrm{~mol} / \mathrm{L}$ at equilibrium). Concerning conditions of equilibration of the solid with the solution, the experimental protocol used was the same as described above with stable $\mathrm{Zn}(\mathrm{II})$. At the end of the sorption stage, ${ }^{65} \mathrm{Zn}(\mathrm{II})$ aqueous activity was determined by gamma counting (Compugamma, LKB Wallac ${ }^{\circledR}$ ). The distribution coefficients (i.e. $\mathrm{Kd}_{\mathrm{ads}}$ ), expressed in ${\mathrm{L} . \mathrm{kg}^{-1}}^{-}$, can then be calculated as follows:

$$
K d_{a d s}=\frac{A_{0}-A}{A} \cdot \frac{V}{m}
$$

where $\mathrm{A}_{0}$ is the initial activity of ${ }^{65} \mathrm{Zn}$ (II) in solution (Bq), $\mathrm{A}$ is the activity of ${ }^{65} \mathrm{Zn}$ (II) in the supernatant at equilibrium $(\mathrm{Bq}), \mathrm{V}$ is the volume of the solution and $\mathrm{m}$ the dry weight $\left(60^{\circ} \mathrm{C}\right)$ of the solid (g).

Provided that no isotope fractionation occurs during $\mathrm{Zn}(\mathrm{II})$ sorption, aqueous $\mathrm{Zn}(\mathrm{II})$ concentration at equilibrium (i.e. [ $\left.\mathrm{Zn}(\mathrm{II})_{\mathrm{aq}}.\right]$ ) can be calculated from $\mathrm{A}_{0}$, $\mathrm{A}$ and the initial 
$\mathrm{Zn}(\mathrm{II})$ aqueous concentration (i.e. $\left[\mathrm{Zn}(\mathrm{II})_{\mathrm{aq}}\right]_{0}$ ) according to the following equation: $\left[\mathrm{Zn}(I I)_{a q .}\right]=\left[\mathrm{Zn}(I I)_{a q .}\right]_{0} \cdot \frac{A}{A_{0}}$

4- Experimental results

"Pech rouge" soil

Figure 5A presents the logarithms of the distribution coefficients for zinc, measured in the sorption stage (i.e. $\mathrm{Kd}_{\mathrm{ads}}$ ), plotted as a function of the logarithm of the aqueous zinc concentration and for different background electrolytes $\left(\mathrm{I}=10^{-2} \mathrm{M} \mathrm{NaCl}-\mathrm{pH}=7.9 \pm 0.1\right.$; $\mathrm{I}=0.5 \mathrm{M} \mathrm{NaCl}-\mathrm{pH}=8.5 \pm 0.1 ; \mathrm{I}=10^{-2} \mathrm{M} \mathrm{CaSO}_{4}-\mathrm{pH}=7.7 \pm 0.1$ ). The three sorption isotherms are obtained at $\mathrm{pH}$ values having the same order of magnitude $\left(\mathrm{pH}_{\min }=7.7 ; \mathrm{pH}_{\max }=8.5\right)$. Consequently, the differences observed between these isotherms cannot be due to competition between the proton and $\mathrm{Zn}(\mathrm{II})_{\mathrm{aq}}$, but rather to competition between $\mathrm{Zn}(\mathrm{II})_{\mathrm{aq}}$. and major cations present in the system (i.e. electrolyte cations). From Figure 5A, we can clearly observe the strong competition of $\mathrm{Ca}^{2+}$ for the sorption sites. Indeed, for the same initial $\mathrm{Zn}$ (II) concentrations in solution, the $\mathrm{Kd}_{\mathrm{ads}}$ values of $\mathrm{Zn}(\mathrm{II})$ measured in $0.01 \mathrm{M} \mathrm{CaSO}$ are lower by a factor of 10 compared with those measured in $\mathrm{NaCl} 0.01 \mathrm{M}$. To a lesser extent, we also find evidence for the competition of $\mathrm{Na}^{+}$, since all $\mathrm{Kd}_{\text {ads }}$ values measured for $\mathrm{Zn}(\mathrm{II})$ in $0.5 \mathrm{M} \mathrm{NaCl}$ are slightly lower than in $0.01 \mathrm{M} \mathrm{NaCl}$.

As already mentioned, we carried out some desorption experiments to check the reversibility of the sorption reaction. For the isotherm obtained in $10^{-2} \mathrm{M} \mathrm{NaCl}$ at $\mathrm{pH}=7.9 \pm 0.1$, Fig. $5 \mathrm{~B}$ shows the $\mathrm{Kd}_{\text {des }}$ measured at the end of the desorption stage compared with values measured at the end of the sorption stage, as a function of the aqueous $\mathrm{Zn}$ (II) concentration at equilibrium. By taking into account the uncertainties of the measurements, we note that the values of desorption $\mathrm{Kd}$ (i.e. $\mathrm{Kd}_{\mathrm{des}}$ ) are superimposed on the sorption $\mathrm{Kd}$ (i.e. $\mathrm{Kd}_{\mathrm{ads}}$ ), suggesting a good reversibility of the exchange reaction. 
Auby sediment

Figure 6 reports the values of $\mathrm{Zn}(\mathrm{II}) \mathrm{Kd}_{\mathrm{ads}}$ obtained with the Auby sediment, plotted as a function of the logarithm of the aqueous zinc concentration, for isotherms carried out in $0.01 \mathrm{M} \mathrm{NaCl}(\mathrm{pH}=7.8 \pm 0.1)$ and $0.01 \mathrm{M} \mathrm{CaSO}_{4}(\mathrm{pH}=7.6 \pm 0.1)$. As mentioned previously in the case of "Pech Rouge", we also observe a strong competition of $\mathrm{Ca}^{2+}$ for the sorption sites. Indeed, for the same initial concentration of zinc in solution, and for comparable $\mathrm{pH}$ and zinc concentration at equilibrium (i.e. $<10^{-6} \mathrm{~mol} / \mathrm{L}$ ), the $\mathrm{Kd}_{\mathrm{ads}}$ of $\mathrm{Zn}(\mathrm{II})$ is approximately comprised between $10^{4}$ and $10^{5}$ in $\mathrm{NaCl}$, whereas $\mathrm{Kd}_{\mathrm{ads}}$ falls to around $10^{3}$ in $\mathrm{CaSO}_{4}$. As mentioned in section 3 , some experiments were performed with the radioactive tracer ${ }^{65} \mathrm{Zn}$ (II) to obtain zinc aqueous concentrations lower than $10^{-7} \mathrm{~mol} / \mathrm{L}$ at equilibrium (see Fig. 6). The $\mathrm{Kd}_{\mathrm{ads}}$ values obtained with radioactive zinc at trace concentrations $\left(10^{-9}<\mathrm{C}_{\mathrm{Zn}(\mathrm{II}) \mathrm{aq} .}<10^{-7} \mathrm{~mol} / \mathrm{L}\right)$ are in agreement with those obtained with stable zinc at higher concentrations (i.e. $>10^{-7} \mathrm{~mol} / \mathrm{L}$ ).

\section{5- Modelling}

In view of the good agreement between sorption and desorption Kd values (see Fig. 5B), we are justified in applying the ion exchange theory, based onto the mass action law, to interpret the experimental data. Assuming that the sorption measured on our natural material (soil or sediment) is only due to clay minerals, the ion exchange model we have developed would be able to reproduce the experimental data obtained for $\mathrm{Zn}$ sorption on sediment/soil under laboratory conditions.

Even though illite is the most abundant clay-mineral phase, montmorillonite makes a predominant contribution to the total site concentration of the bulk material. Indeed, the typical ion-exchange site concentration for illite is $0.22 \mathrm{~mol} / \mathrm{kg}$ (Poinssot et al., 1999), whereas it is around $0.88 \mathrm{~mol} / \mathrm{kg}$ for montmorillonite. Therefore, the contributions of each of these phases to the total site concentration are $30 \%$ for illite and $70 \%$ for montmorillonite.

In our model, we assume that the exchange sites of montmorillonite and illite have similar chemical reactivities. Therefore, the ion exchanger is composed solely of montmorillonite, whose total site concentration corresponds to the CEC measured for the soils/sediments. For the Auby sediment, the measured CEC is equivalent to $22 \%$ of pure montmorillonite, while for the Pech Rouge soil, the relative abundance is only $16 \%$. The concentrations of each of the exchange sites are calculated according to the relative concentration of sites on pure 
montmorillonite. The choice of montmorillonite as a reference clay mineral for $\mathrm{Zn}$ (II) sorption is supported by the high quality of experimental data reported by Baeyens and Bradbury (1997), whereas such data are missing or incomplete for other clay minerals.

We used the sorption parameters defined in section 2 (see table 2) for modelling of the $\mathrm{Zn}$ (II) sorption isotherms obtained for the sediment and soil. Figure 7 shows a comparison of the experimental Kd obtained for the "Pech Rouge" soil with values predicted by the model, for experiments performed in $10^{-2} \mathrm{M} \mathrm{NaCl}$ (Fig. 7A) and $0.5 \mathrm{M} \mathrm{NaCl}$ (Fig. 7B). Whatever the $\mathrm{NaCl}$ concentration used and the zinc concentration in solution, we obtain a good agreement between the predicted and measured Kd datasets. However, the model leads to a small underestimation when the value of the ionic strength is $0.5 \mathrm{M}(\mathrm{NaCl})$. In this case, we see that the contribution of the site " 0 " to zinc sorption is practically negligible compared to the major sites (see Fig. 7B). Under these conditions (i.e. $0.5 \mathrm{M} \mathrm{NaCl}$ ), $\mathrm{Na}^{+}$is the dominant species sorbed onto the site " 0 ”, despite its lower selectivity coefficient compared to $\mathrm{Zn}^{2+}$, which has much lower concentration in solution (i.e. from $10^{-5}$ to $4.10^{-4} \mathrm{M}$ ).

As comparison, we also tested the Bradbury and Baeyens model (1997). The results of the two models in the case of sorption of $\mathrm{Zn}$ (II) onto the Pech Rouge soil in $0.5 \mathrm{M} \mathrm{NaCl}$ solution at $\mathrm{pH}=8.5$ are compared on the figure $7 \mathrm{~B}$. In this case, the Bradbury and Baeyens model clearly underestimates the sorption of $\mathrm{Zn}$ (II) for metal concentrations between $10^{-6}$ and $10^{-4}$ M. In presence of high $\mathrm{Na}^{+}$concentration it appears difficult to describe with a good agreement the competition between $\mathrm{Zn}(\mathrm{II}), \mathrm{Na}^{+}$and $\mathrm{H}^{+}$with using a single ion-exchange site, the only one being operational in these conditions. So, since the sorption contribution of edge sites is not predominant, model with a single ion-exchange site is probably too restrictive.

Besides the fact that protons is explicitly taken into account in the ion-exchange reactions, the main advantage of our approach is to describe the reactivity of the surface minerals by several ion-exchange sites with a homogeneous formalism. Therefore, this approach is particularly well adapted to represent sorption in various chemical conditions, over a wide range of metal concentrations $\left(10^{-4}-10^{-8} \mathrm{M}\right)$, and for various $\mathrm{pH}$.

To interpret the experimental data obtained in $0.01 \mathrm{M} \mathrm{CaSO}_{4}$, additional data are required to describe $\mathrm{Zn}^{2+} / \mathrm{Ca}^{2+}$ competition for sorption sites. Consequently, we used the selectivity coefficient for the $2 \mathrm{H} / \mathrm{Ca}$ exchange reaction onto montmorillonite, as determined by Nolin (1997) (see Table 2). Figure 8 compares the experimental Kd values with results predicted by the model in the case of the isotherm obtained using $0.01 \mathrm{M} \mathrm{CaSO}_{4}$ solution. We observe that the model slightly underestimates $\mathrm{Kd}$ values. This behaviour is partly explained by the 
overestimation of the $\mathrm{K}_{2 \mathrm{H} / \mathrm{Ca}}$ ion exchange constant associated with the major sites. Ideally, modelling of $\mathrm{Zn}$ (II) sorption in the presence of $\mathrm{Ca}^{2+}$ as a major competitor would be improved by conducting new sorption experiments on a Ca-conditioned montmorillonite. This would lead to a better characterization of the $2 \mathrm{H} /$ Ca selectivity coefficient for each of the sites.

Figure 9 reports the sorption isotherms obtained with the Auby sediment in $10^{-2} \mathrm{M} \mathrm{NaCl}$ and $10^{-2} \mathrm{M} \mathrm{CaSO}_{4}$ aqueous solutions. Calculated $\mathrm{Kd}$ values are compared with the measured $\mathrm{Kd}_{\mathrm{ads}}$ in these different aqueous media. By taking into account uncertainties on the experimental measurements, there is a relatively good match between predicted and experimental $\mathrm{Kd}_{\mathrm{ads}}$ values.

Figure 9 also illustrates the contribution of the three major sites and the site low-capacity site to the sorption of zinc onto the sediment. For aqueous zinc concentrations higher than $10^{-7}$ $\mathrm{mol} / \mathrm{L}$ at equilibrium, the sorption can be explained solely by the contributions of the major sites, whatever the nature of the electrolyte considered (i.e. $\mathrm{NaCl}$ or $\mathrm{CaSO}_{4}$ ). For $[\mathrm{Zn}(\mathrm{II})]_{\mathrm{aq} .}<10^{-8} \mathrm{~mol} / \mathrm{L}$, we also observe that sorption is strongly influenced by the site having a low capacity (i.e. site “0”).

Table 2 presents the complete ion-exchange model proposed in this study to interpret the experimental data. It includes i) site densities used for each mineralogical assemblage, and whose the sum corresponds to the measured CEC, and ii) the H/Na, $2 \mathrm{H} / \mathrm{Ca}$ and $2 \mathrm{H} / \mathrm{Zn}$ selectivity coefficients obtained previously for montmorillonite.

\section{Conclusion:}

The modelling approach we have developed shows that the multi-site ion exchange model is a good alternative for predicting sorption processes onto pure clay mineral phases or components of more complex materials such as soil or sediment. Clay minerals can be considered as multi-site ion-exchangers, in which each of the sites is characterized in terms of site concentration and affinity for different cations as against protons.

This approach is successfully applied to interpret $\mathrm{Zn}(\mathrm{II})$ sorption experimental data obtained by Baeyens and Bradbury on pure Na-montmorillonite. Combining the sorption properties previously determined on pure clay minerals and treating Baeyens and Bradbury's raw data 
with the same formalism, we can propose a consistent ion exchange thermodynamic database, including the more common cations encountered in natural environments. In a second step, this database is successfully used, without any adjustment, to reproduce experimental sorption data obtained for $\mathrm{Zn}$ (II) on both soil and sediment, and under a wide range of chemical conditions.

This study represents a first stage towards an application to more complex environmental contexts. In our view, multiple ion-exchange sites should be taken into account, as well as their affinity towards protons and the various cations potentially present in the environment, in order to improve the description of sorption processes in natural systems. Such an approach would particularly favour our ability to predict the impact of competitor cations on the mobility of contaminants in the environment.

\section{Acknowledgements}

This research was supported by grants from CEA (Commissariat à l'Energie Atomique, France). The authors would like to thank two anonymous reviewers for their substantial contributions to improving the paper. We are also grateful to P. Meier and M. Herbette for their assistance in the $\gamma$-activity measurements. We also thank Dr J. Ly for constructive discussions about the ion-exchanger model. M. Carpenter post-edited the English style.

Associate editor: Rob N.J. Comans.

References

Alliot, C., Bion, L., Mercier, F., Toulhoat, P., 2005. Sorption of aqueous carbonic, acetic, and oxalic acids onto $\alpha$-alumina. J. Colloid Interf. Sci. 287, 444-451.

Appelo, C.A.J., Van-der-Weiden, M.J.J., Tournassat, C., Charlet, L., 2002. Surface complexation of ferrous iron and carbonate on ferrihydrite and the mobilization of arsenic. Environ. Sci. Technol. 36, 3096-3103. 
Avena, M. J., De Pauli, C. P., 1998. Proton adsorption and electrokinetics of an Argentinean montmorillonite. J. Colloid Interf. Sci. 202, 195-204.

Baeyens, B., Bradbury, M.H., 1997. A mechanistic description of Ni and Zn sorption on Namontmorillonite. Part I: Titration and sorption measurements. J. Contam. Hydrol. 27, 199222.

Beaucaire C., 2005. Rétention du strontium en milieu naturel : application de la théorie des échangeurs d’ions (1/2) NT DPC/SECR 5-014.

Beaucaire, C., Coreau, N., Legrand, S., Devineau, S., 2006. Rétention du strontium en milieu naturel : application de la théorie des échangeurs d’ions (2/2) NT DPC/SECR 06-044-A.

Benjamin, M.M., Leckie, J.O., 1981. Multi-site adsorption of Cd, Zn and Pb on amorphous iron oxyhydroxide. J. Colloid Interf. Sci. 79, 209-221.

Bradbury, M.H., Baeyens, B., 1997. A mechanistic description of Ni and Zn sorption on Namontmorillonite. Part II: modeling. J. Contam. Hydrol. 27, 223-248.

Curti, E., Kulik, D.A., Tits, J., 2005. Solid solutions of trace Eu(III) in calcite: thermodynamic evaluation of experimental data over a wide range of $\mathrm{pH}$ and $\mathrm{pCO}_{2}$. Geochim. Cosmochim. Acta 69, 1721-1737.

Davis, J.A., Fuller, C.C., Cook, A.D., 1987. A model for trace metal sorption processes at the calcite surface: adsorption of $\mathrm{Cd}^{2+}$ and subsequent solid solution formation. Geochim. Cosmochim. Acta 51, 1477-1490.

Davis, J.A., Coston, J.A., Kent, D.B., Fuller, C.C., 1998. Application of the surface complexation concept to complex mineral assemblages. Environ. Sci. Technol. 32, 28202828.

Davis, J.A., Meece, D.E., Kohler, M., Curtis, G.P., 2004. Approaches to surface complexation modeling of Uranium (VI) adsorption on aquifer sediments. Geochim. Cosmochim. Acta 68, 3621-3641. 
Dzombak, D.A., Morel, F.M.M., 1990. Surface complexation modeling hydrous ferric oxide, Wiley-Interscience, New York.

El Aamrani, F.Z., Duro, L., De Pablo, J., Bruno, J., 2002. Experimental study and modeling of the sorption of uranium (VI) onto olivine-rock. Appl. Geochem. 17, 399-408.

Fernandez, J..M., Juncos, C., Géniaut, G., 2000. Etude de la migration du 90Sr de la parcelle expérimentale de Pech Rouge : (1) caractérisation et analyse de risque. NT SEP2000/233.

Fletcher, P., Sposito, G., 1989. The chemical modeling of clay/electrolyte interactions for montmorillonite. Clay Miner. 24, 375-391.

Gaucher, E., 1998. Interactions eaux-argiles : étude expérimentale. Ph. D. Thesis, Univ. Paris 7.

Gorgeon, L., 1994. Contribution à la modélisation physico-chimique de la rétention de radioéléments à vie longue par des matériaux argileux. Ph. D. Thesis, Univ. Paris 6.

Gu, X., Evans, L.J., 2007. Modelling the adsorption of Cd(II), Cu(II), Ni(II), Pb(II) and Zn(II) onto Fithian illite. J. Colloid Interf. Sci. 307, 317-325.

Jacquier, P., Ly, J., Beaucaire, C., 2004. The ion-exchange properties of the Tournemire argilite I. Study of the H, Na, K, Cs, Ca and Mg behaviour. Appl. Clay Sci. 26, 163-170.

Johnson, J.W., Oelkers, E.H., Helgeson, H.C., 1992. SUPCRT92: a software package for calculating the standard molars thermodynamic properties of minerals; gases, aqueous species and reactions from 1 to 5000 bars and 0 to $1000^{\circ} \mathrm{C}$. Comput. Geosci. 18, 899-947.

Kurosawa, S., James, S.C., Yui, M., Ibaraki, M., 2006. Model analysis of the colloid and radionuclide retardation experiment at the Grimsel Test Site. J. Colloid Interf. Sci. 298, 467475. 
Lions, J., 2004. Etude hydrogéochimique de la mobilité de polluants inorganiques dans des sédiments de curage mis en dépôt : expérimentations, mesures in situ et modélisations. Ph. D. Thesis, ENSCP.

Ly, J., Pitsch, H., Stammose, D., 1991. Description of actinides sorption onto clays by ionexchange mechanism. Migration 91, Jerez de la Frontera, Espagne.

Maes, A., Peigneur, P., Cremers, A., 1976. Thermodynamics of transition metal ion exchange in montmorillonite. Proc. Int. Clay Conference 1975, Applied Publ. Wilmette, IL.

Missana, T., Garcia-Gutierrez, M., Alonso, U., 2004. Kinetics and irreversibility of cesium and uranium sorption onto bentonite colloids in a deep granitic environment. Appl. Clay Sci. 26, 137-150.

Motellier, S., Ly, J., Gorgeon, L., Charles, Y., Hainos, D., Meier, P., Page, J., 2003. Modelling of the ion-exchange properties and indirect determination of the interstitial water composition of an argillaceous rock. Application to the Callovo-Oxfordian low-water-content formation. Appl. Geochem. 18, 1517-1530.

Mustafa, G., Singh, B., Kookana, R.S., 2004. Cadmium adsorption and desorption behaviour on goethite at low equilibrium concentrations: effects of $\mathrm{pH}$ and index cations. Chemosphere $57,1325-1333$.

Nolin, D., 1997. Rétention de radioéléments à vie longue par des matériaux argileux. Influence d'anions contenus dans les eaux naturelles. Ph. D. Thesis, Univ. Paris 6.

Parkhurst, D.L,. Appelo, C.A.J., 1999. Phreeqc2 user’s manual and program U.S. Geological Survey.

Payne, T.E., Davis, A.D., Ochs, M., Olin, M., Tweed, C.J., 2004. Uranium adsorption on weathered schist - intercomparison of modeling approaches. Radiochim. Acta 92, 651-661. 
Pivovarov, S., 2005. Modeling of ionic equilibria of trace metals $\left(\mathrm{Cu}^{2+}, \mathrm{Zn}^{2+}, \mathrm{Cd}^{2+}\right)$ in concentrated aqueous electrolyte solutions at $25^{\circ} \mathrm{C}$. J. Colloid Interf. Sci. 291, 421-432.

Poinssot, C., Baeyens, B., Bradbury, M. H., 1999. Experimental and modelling studies of caesium sorption on illite. Geochim. Cosmochim. Acta 63, 3217-3227.

Rimstidt, J.D., Balog, A., Webb, J., 1998. Distribution of trace elements between carbonate minerals and aqueous solutions. Geochim. Cosmochim. Acta 62, 1851-1863.

Ringböm, A., 1963. Complexation in Analytical Chemistry. Ed. Interscience, New York.

Sposito, G., Jouany, C., Holtzclaw, K.M., Levesque, C.S., 1983. Calcium-Magnesium exchange on Wyoming bentonite in the presence of adsorbed sodium. Soil Sci. Soc. Am. J., 47, 1081-1085.

Steefel, C.I., Caroll, S., Zhao, P., Roberts, S., 2003. Cesium migration in Hanford sediment: a multisite cation exchange model based on laboratory transport experiments. J. Contam. Hydrol. 67, 219-246.

Stumpf, S., Stumpf, T., Lutzenkirchen, J., Walther, C., Fanghänel, T., 2008. Immobilization of trivalent actinides by sorption onto quartz and incorporation into siliceous bulk: investigations by TRLFS. J. Colloid Interf. Sci. 318, 5-14.

Takahashi, Y., Murata, M., Kimura, T., 2006. Interaction of Eu(III) ion and non-porous silica: Irreversible sorption of $\mathrm{Eu}(\mathrm{III})$ on silica and hydrolysis of silica promoted by Eu(III). J. Alloys Compd. 408-412, 1246-1251.

Tertre, E., Castet, S., Berger, G., Loubet, M., Giffaut, E., 2006a. Surface chemistry of kaolinite and Na-montmorillonite in aqueous electrolyte solutions at 25 and $60^{\circ} \mathrm{C}$ : experimental and modeling study. Geochim. Cosmochim. Acta 70, 4579-4599.

Tertre, E., Berger, G., Simoni, E., Castet, S., Giffaut, E., Loubet, M., Catalette, H, 2006b. Europium retention onto clay minerals from 25 to $150^{\circ} \mathrm{C}$ : experimental measurements, spectroscopic features and sorption modelling. Geochim. Cosmochim. Acta 70, 4563-4578. 
Tesoriero, A.J., Pankow, J.F., 1996. Solid solution partitioning of $\mathrm{Sr}^{2+}, \mathrm{Ba}^{2+}$ and $\mathrm{Cd}^{2+}$ to calcite. Geochim. Cosmochim. Acta 60, 1053-1063.

Tombacz, E., Szekeres, M., 2004. Colloidal behavior of aqueous montmorillonite suspensions: the specific role of $\mathrm{pH}$ in the presence of indifferent electrolytes. Appl. Clay Sci. 27, 75-94.

Tournassat, C., Greneche, J.M., Tisserand, D., Charlet, L., 2004a. The titration of clay minerals. Part I. Discontinuous backtitration technique combined to CEC measurements. J. Colloid Interf. Sci. 273, 224-233.

Tournassat, C., Ferrage, E., Poinsignon, C., Charlet, L., 2004b. The titration of clay minerals. Part II. Structure based model and implications for clay reactivity. J. Colloid Interf. Sci. 273, 234-246.

Tran, Y.T., Barry, D.A., Bajracharya, K., 2002. Cadmium desorption in sand. Environ. Int. 28, 493-502.

Trivedi, P., Dyer, J.A., Sparks, D.L., Pandya, K., 2004. Mechanistic and thermodynamic interpretations of zinc sorption onto ferrihydrite. J. Colloid Interf. Sci. 270, 77-85.

Turner, G. D., Zachara, J.M., McKinley, J.P., Smith, S.C.,1996. Surface-charge properties and $\mathrm{UO}_{2}{ }^{2+}$ adsorption of a subsurface smectite. Geochim. Cosmochim. Acta 60, 3399-3414.

Turner, D.R., Pabalan, R.T., Beretti, F.P., 1998. Neptunium (V) sorption on montmorillonite: An experimental and surface complexation modeling study. Clays Clay Mineral. 46, 256269.

Vandenhove, H., Van Hees, M., Wouters, K., Wannijn, J., 2007. Can we predict uranium bioavailability based on soil parameters? Part 1: Effect of soil parameters on soil solutions uranium concentration. Environ. Pollut. 145, 587-595.

Villalobos, M., Leckie, J.O., 2001. Surface complexation modeling of carbonate effects on the adsorption of Cr(III), Pb(II) and U(VI) on goethite. Environ. Sci. Technol. 35, 3849-3856. 
Wolthers, M., Charlet, L., Tournassat, C., 2006. Reactivity of bentonite: an additive model applied to uranyl sorption. In: Lützenkirchen, J. (Ed.), Interface Science and Technology, vol. 11. Elsevier Ltd as an Academic Press imprint, 539-552 (Chapter 20).

Zachara, J.M., Cowan, C.E., Resch, C.T., 1991. Sorption of divalent metals on calcite. Geochim. Cosmochim. Acta 55, 1549-1562. 
Table captions:

Table 1: Site concentrations and selectivity coefficients for the $\mathrm{H} / \mathrm{Na}$ exchange reaction onto Wyoming Na-montmorillonite. Values proposed by Nolin (1997).

Table 2: Site concentrations and selectivity coefficients proposed in this study to interpret i) experimental data reported by Baeyens and Bradbury (1997) concerning sorption of Zn(II) onto Wyoming Na-montmorillonite, and ii) sorption $\mathrm{Zn}(\mathrm{II})$ isotherms obtained in this study using Pech Rouge soil and Auby sediment...... 


\begin{tabular}{|c|c|c|}
\hline 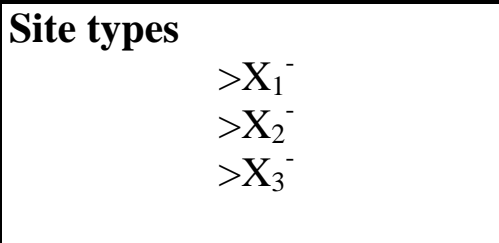 & $\begin{array}{c}\begin{array}{c}\text { Site concentrations } \\
\text { (mol//kg) }\end{array} \\
0.387 \\
0.361 \\
0.139\end{array}$ & $\begin{array}{l}\text { Observations } \\
\qquad \begin{array}{l}\text { From Nolin (1997) } \\
\text { The sum of the three site } \\
\text { concentrations (i.e. } 0.89\end{array}\end{array}$ \\
\hline $\begin{array}{l}\text { Ion exchange reaction } \\
>\mathrm{X}_{1} \mathrm{H}+\mathrm{Na}^{+}=>\mathrm{X}_{1} \mathrm{Na}+\mathrm{H}^{+} \\
>\mathrm{X}_{2} \mathrm{H}+\mathrm{Na}^{+}=>\mathrm{X}_{2} \mathrm{Na}+\mathrm{H}^{+} \\
>\mathrm{X}_{3} \mathrm{H}+\mathrm{Na}^{+}=>\mathrm{X}_{3} \mathrm{Na}+\mathrm{H}^{+}\end{array}$ & $\begin{array}{c}\log { }^{*} \mathbf{K}_{\mathbf{H} / \mathrm{Na}} \\
-0.32 \\
-2.87 \\
-8.86\end{array}$ & $\begin{array}{l}\mathrm{mol} / \mathrm{kg} \text { ) is in good agreement } \\
\text { with the total measured CEC } \\
\text { (i.e. } 0.88 \mathrm{~mol} / \mathrm{kg} \text { ) }\end{array}$ \\
\hline
\end{tabular}

Table 1: Site concentrations and selectivity coefficients for the H/Na exchange reaction onto Wyoming Na-montmorillonite. Values proposed by Nolin (1997). 


\begin{tabular}{|c|c|c|c|}
\hline & Site types & $\begin{array}{c}\text { Site } \\
\text { concentrations } \\
(\mathbf{m o l} / \mathbf{k g}) \\
\end{array}$ & Observations \\
\hline \multirow[t]{2}{*}{$\begin{array}{c}\text { Pure Na- } \\
\text { montmorillonite }\end{array}$} & $>\mathrm{X}_{0}^{-}$ & $5.10^{-3}$ & $\begin{array}{c}\text { Obtained by fitting the } \\
\text { experimental data from } \\
\text { Baeyens and Bradbury (1997) }\end{array}$ \\
\hline & $\begin{array}{l}>\mathrm{X}_{1}^{-} \\
>\mathrm{X}_{2}^{-} \\
>\mathrm{X}_{3}^{-}\end{array}$ & $\begin{array}{l}0.387 \\
0.361 \\
0.139\end{array}$ & Nolin (1997) \\
\hline \multirow{2}{*}{$\begin{array}{l}\text { Pech Rouge } \\
\text { soil }\end{array}$} & $>\mathrm{X}_{0}^{-}$ & $5.10^{-3}$ & \multirow{2}{*}{$\begin{array}{c}\text { Total site } \\
\text { concentrations=0.142 mol/kg; } \\
\text { In agreement with the } \\
\text { measured CEC (i.e. } 0.141 \\
\mathrm{~mol} / \mathrm{kg})\end{array}$} \\
\hline & $\begin{array}{l}>\mathrm{X}_{1}^{-} \\
>\mathrm{X}_{2}^{-} \\
>\mathrm{X}_{3}^{-}\end{array}$ & $\begin{array}{l}0.387 \\
0.361 \\
0.139\end{array}$ & \\
\hline \multirow[t]{6}{*}{ Auby sediment } & $>\mathrm{X}_{0}^{-}$ & $5.10^{-3}$ & \multirow{2}{*}{$\begin{array}{c}\text { Total site } \\
\text { concentrations=0.198 mol/kg; } \\
\text { In agreement with the } \\
\text { measured CEC (i.e. } 0.199 \\
\mathrm{~mol} / \mathrm{kg} \text { ) }\end{array}$} \\
\hline & $\begin{array}{l}>\mathrm{X}_{1}^{-} \\
>\mathrm{X}_{2}^{-} \\
>\mathrm{X}_{3}^{-}\end{array}$ & $\begin{array}{l}0.387 \\
0.361 \\
0.139\end{array}$ & \\
\hline & Ion-exchange reaction & $\log ^{*} \mathrm{~K}\left(25^{\circ} \mathrm{C}\right)$ & Observations \\
\hline & $>\mathrm{X}_{0} \mathrm{H}+\mathrm{Na}^{+}=>\mathrm{X}_{0} \mathrm{Na}+\mathrm{H}^{+}$ & -5.1 & $\begin{array}{c}\text { Obtained by fitting the } \\
\text { experimental data from } \\
\text { Baeyens and Bradbury (1997) }\end{array}$ \\
\hline & $\begin{array}{l}>\mathrm{X}_{1} \mathrm{H}+\mathrm{Na}^{+}=>\mathrm{X}_{1} \mathrm{Na}+\mathrm{H}^{+} \\
>\mathrm{X}_{2} \mathrm{H}+\mathrm{Na}^{+}=>\mathrm{X}_{2} \mathrm{Na}+\mathrm{H}^{+} \\
>\mathrm{X}_{3} \mathrm{H}+\mathrm{Na}^{+}=>\mathrm{X}_{3} \mathrm{Na}+\mathrm{H}^{+}\end{array}$ & $\begin{array}{l}-0.32 \\
-2.87 \\
-8.86\end{array}$ & Nolin (1997) \\
\hline & $\begin{array}{l}>2 \mathrm{X}_{0} \mathrm{H}+\mathrm{Zn}^{2+}=>\left(\mathrm{X}_{0}\right)_{2} \mathrm{Zn}+2 \mathrm{H}^{+} \\
>2 \mathrm{X}_{1} \mathrm{H}+\mathrm{Zn}^{2+}=>\left(\mathrm{X}_{1}\right)_{2} \mathrm{Zn}+2 \mathrm{H}^{+} \\
>2 \mathrm{X}_{2} \mathrm{H}+\mathrm{Zn}^{2+}=>\left(\mathrm{X}_{2}\right)_{2} \mathrm{Zn}+2 \mathrm{H}^{+} \\
>2 \mathrm{X}_{3} \mathrm{H}+\mathrm{Zn}^{2+}=>\left(\mathrm{X}_{3}\right)_{2} \mathrm{Zn}+2 \mathrm{H}^{+}\end{array}$ & $\begin{array}{l}-2.5 \\
0.13 \\
-4.26 \\
-10.0\end{array}$ & $\begin{array}{c}\text { Obtained by fitting the } \\
\text { experimental data from } \\
\text { Baeyens and Bradbury (1997) }\end{array}$ \\
\hline
\end{tabular}

Table 2: Site concentrations and selectivity coefficients proposed in this study to interpret i) experimental data reported by Baeyens and Bradbury (1997) concerning sorption of Zn(II) onto Wyoming Na-montmorillonite, and ii) sorption Zn(II) isotherms obtained in this study using Pech Rouge soil and Auby sediment. 
Figure captions:

Figure 1: Concentration of sodium sorbed onto Wyoming Na-montmorillonite as a function of $\mathrm{pH}$.Comparison between experimental results reported by Nolin (1997) and data calculated from ion-exchange model using three major sites for sorption (see Table 1 for parameters). $\mathrm{I}=0.1 \mathrm{M} \mathrm{NaClO}_{4}$

Figure 2: Logarithm of the distribution coefficients of $\mathrm{Zn}$ (II) between Wyoming montmorillonite and $0.1 \mathrm{M} \mathrm{NaClO}_{4}$ solutions as a function of the aqueous zinc concentration at equilibrium and for different $\mathrm{pH}$ (A: $\mathrm{pH}=5.6$; $\mathrm{B}$ : $\mathrm{pH}=7.0)$. Symbols refer to experimental measurements of Baeyens and Bradbury (1997), whereas curves indicate ion-exchange modelling without considering site " 0 " (i.e. site having low density and strong affinity)....

Figure 3: Logarithm of the distribution coefficients of $\mathrm{Zn}(\mathrm{II})$ between Wyoming montmorillonite and $0.1 \mathrm{M} \mathrm{NaClO}_{4}$ solutions as a function of the aqueous zinc concentration at equilibrium and for different $\mathrm{pH}(\mathrm{A}: \mathrm{pH}=5.6$; $\mathrm{B}: \mathrm{pH}=7.0)$. Symbols refer to experimental measurements of Baeyens and Bradbury (1997), whereas curves indicate ion-exchange modelling which includes site "0", the site having low density and strong affinity.

Figure 4: Comparison between experimental $\mathrm{Kd}$ of $\mathrm{Zn}(\mathrm{II})$, measured by Baeyens and Bradbury (1997) onto a montmorillonite, and values predicted by ion-exchange modelling versus $\mathrm{pH}$. The model is presented in Table 2. $\mathrm{I}=0.1 \mathrm{M} \mathrm{NaClO}_{4}$.

Figure 5: Logarithm of the distribution coefficient for zinc sorbed onto Pech Rouge soil as a function of aqueous zinc concentrations in different background solutions. Experimental data obtained at the end of the sorption stage (A). Comparison between data obtained at the end of the sorption and desorption stages (B)

Figure 6: Logarithm of the distribution coefficient for zinc sorbed onto Auby sediment as a function of the aqueous zinc concentrations in different background solutions.

Figure 7: Comparison between measured (symbols) and predicted (continuous lines) Kd data for $\mathrm{Zn}(\mathrm{II})$, as a function of the aqueous zinc concentration. Case of isotherms obtained for the "Pech Rouge" soil in (A) $10^{-2} \mathrm{M} \mathrm{NaCl}(\mathrm{pH}=7.9 \pm 0.1)$ and (B) $0.5 \mathrm{M} \mathrm{NaCl}$ $(\mathrm{pH}=8.5 \pm 0.1)$.

Figure 8: Comparison between measured (symbols) and predicted (continuous lines) Kd data for $\mathrm{Zn}(\mathrm{II})$, as a function of the aqueous zinc concentration. Case of isotherms obtained

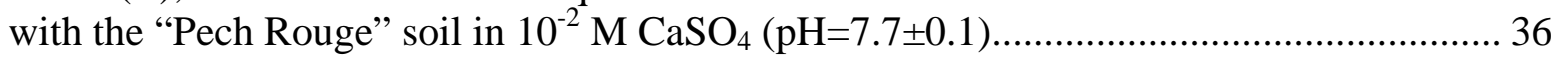

Figure 9: Comparison between measured (symbols) and predicted (continuous lines) Kd data for $\mathrm{Zn}(\mathrm{II})$, as a function of the aqueous zinc concentration. Case of isotherms obtained with the "Auby" sediment in (A) $10^{-2} \mathrm{M} \mathrm{NaCl}(\mathrm{pH}=7.8 \pm 0.1)$ and (B) $10^{-2} \mathrm{M} \mathrm{CaSO}_{4}$ $(\mathrm{pH}=7.6 \pm 0.1)$. 


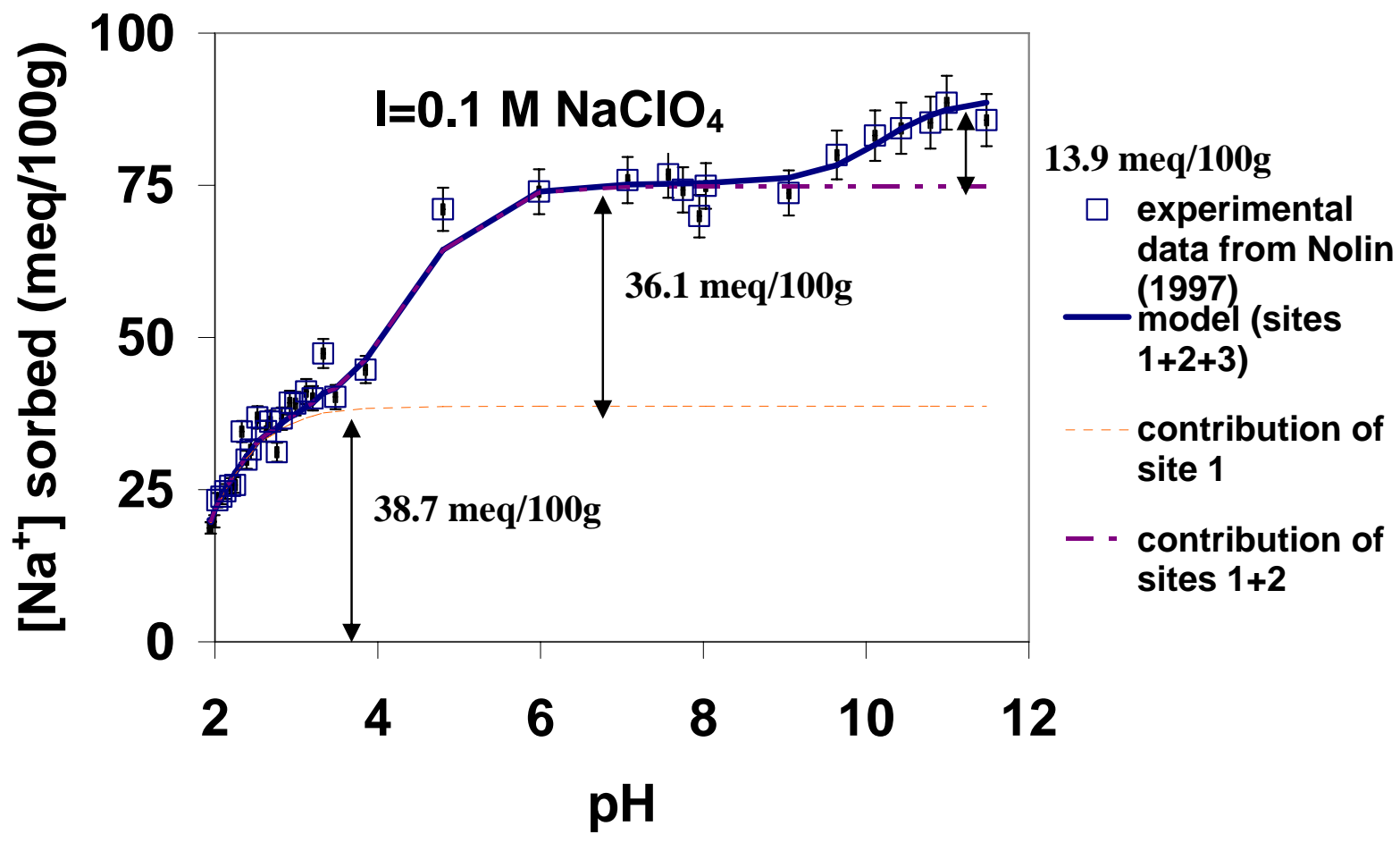

Figure 1: Concentration of sodium sorbed onto Wyoming Na-montmorillonite as a function of $\mathrm{pH}$.Comparison between experimental results reported by Nolin (1997) and data calculated from ion-exchange model using three major sites for sorption (see Table 1 for parameters). $\mathrm{I}=0.1 \mathrm{M} \mathrm{NaClO}_{4}$ 
(A) : $\mathrm{pH}=5.6$

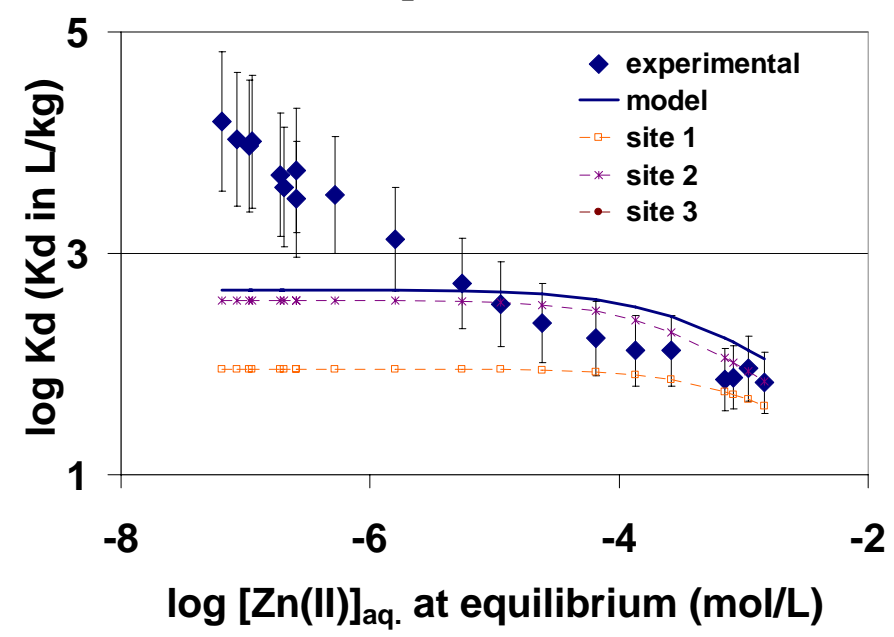

(B) : $\mathbf{p H}=7.0$

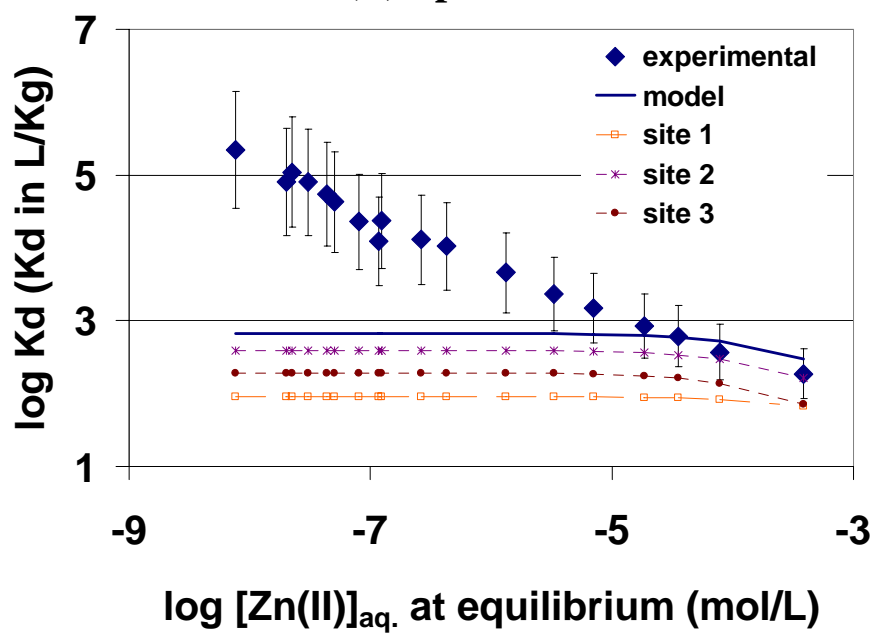

Figure 2: Logarithm of the distribution coefficients of $\mathrm{Zn}(\mathrm{II})$ between Wyoming montmorillonite and $0.1 \mathrm{M} \mathrm{NaClO}_{4}$ solutions as a function of the aqueous zinc concentration at equilibrium and for different $\mathrm{pH}(\mathrm{A}: \mathrm{pH}=5.6$; $\mathrm{B}: \mathrm{pH}=7.0)$. Symbols refer to experimental measurements of Baeyens and Bradbury (1997), whereas curves indicate ion-exchange modelling without considering site "0" (i.e. site having low density and strong affinity) 
(A) : $\mathrm{pH}=5.6$

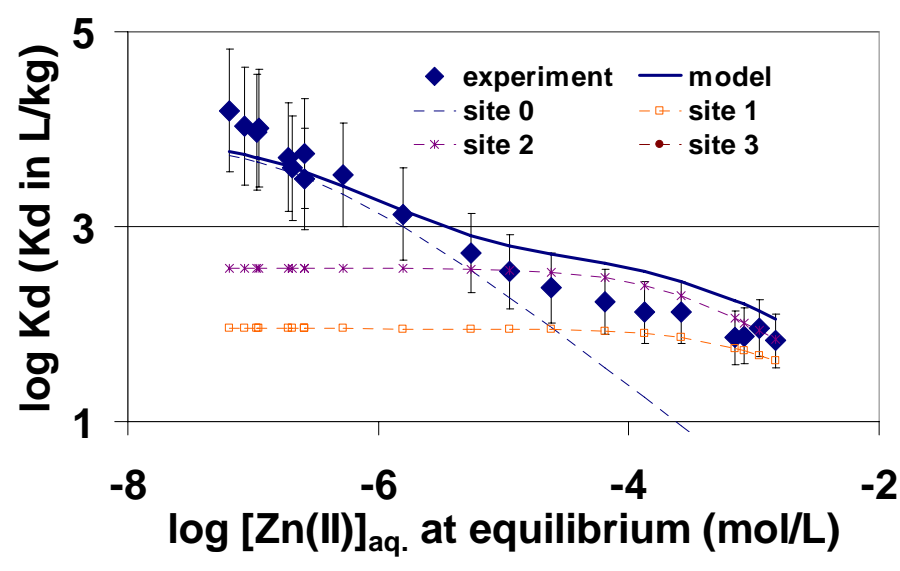

(B) : $\mathbf{p H}=7.0$

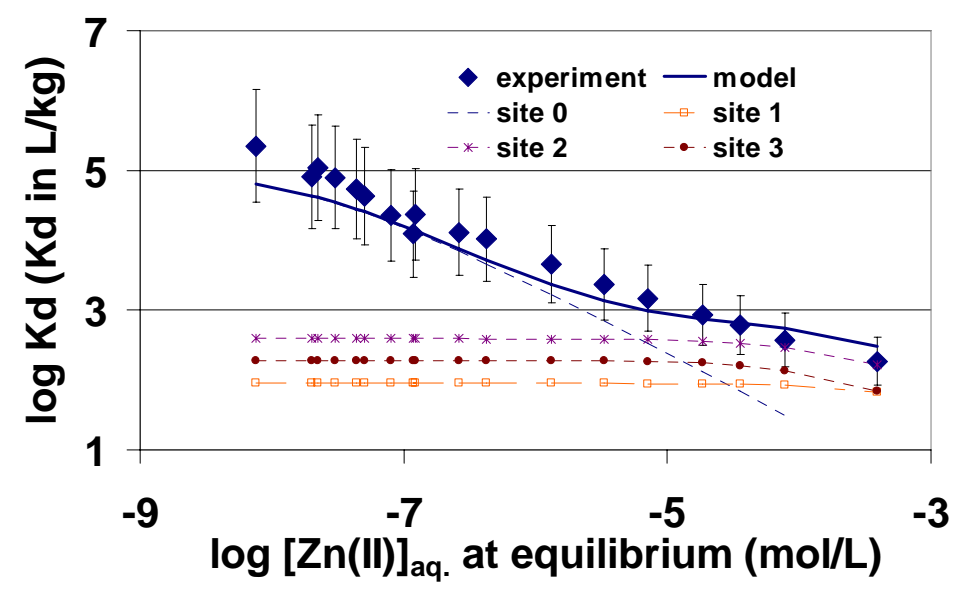

Figure 3: Logarithm of the distribution coefficients of $\mathrm{Zn}(\mathrm{II})$ between Wyoming montmorillonite and $0.1 \mathrm{M} \mathrm{NaClO}_{4}$ solutions as a function of the aqueous zinc concentration at equilibrium and for different $\mathrm{pH}(\mathrm{A}$ : $\mathrm{pH}=5.6$; $\mathrm{B}$ : $\mathrm{pH}=7.0)$. Symbols refer to experimental measurements of Baeyens and Bradbury (1997), whereas curves indicate ion-exchange modelling which includes site " 0 ”, the site having low density and strong affinity. 


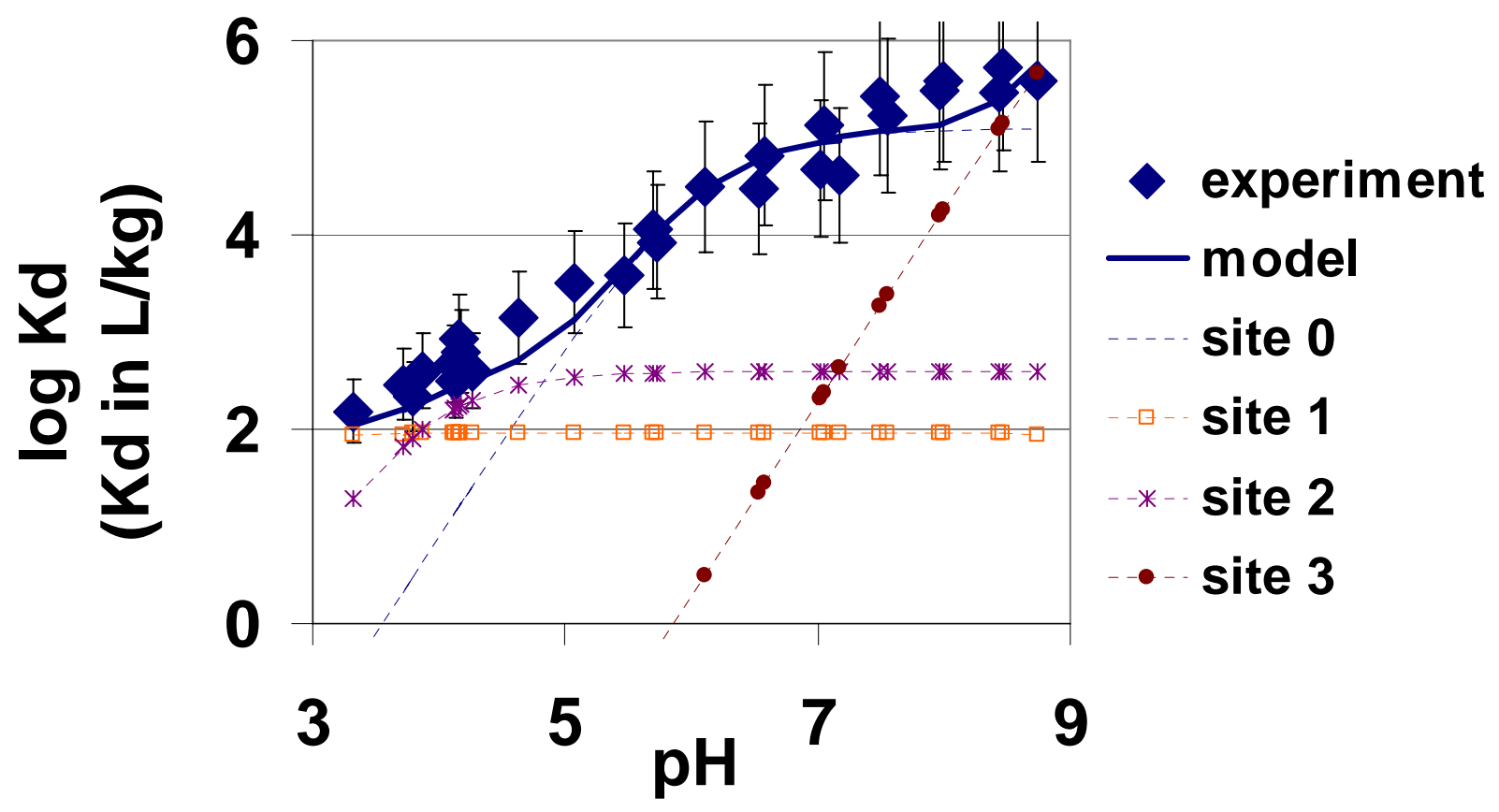

Figure 4: Comparison between experimental $\mathrm{Kd}$ of $\mathrm{Zn}(\mathrm{II})$, measured by Baeyens and Bradbury (1997) onto a montmorillonite, and values predicted by ion-exchange modelling versus $\mathrm{pH}$. The model is presented in Table $2 . \mathrm{I}=0.1 \mathrm{M} \mathrm{NaClO}_{4}$. 


\section{A: Sorption onto Pech Rouge soil}

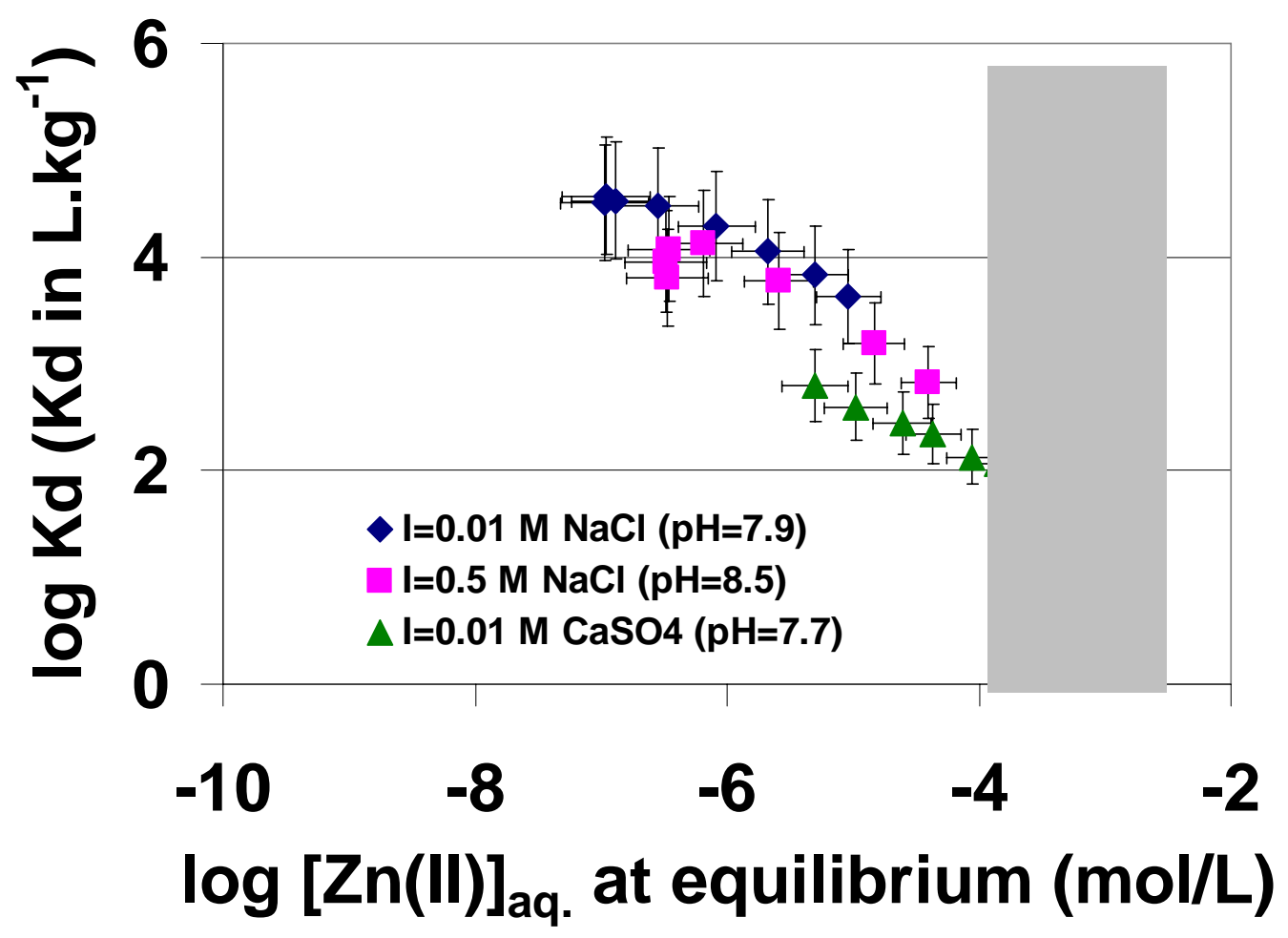

\section{B: Sorption and desorption onto Pech Rouge soil}

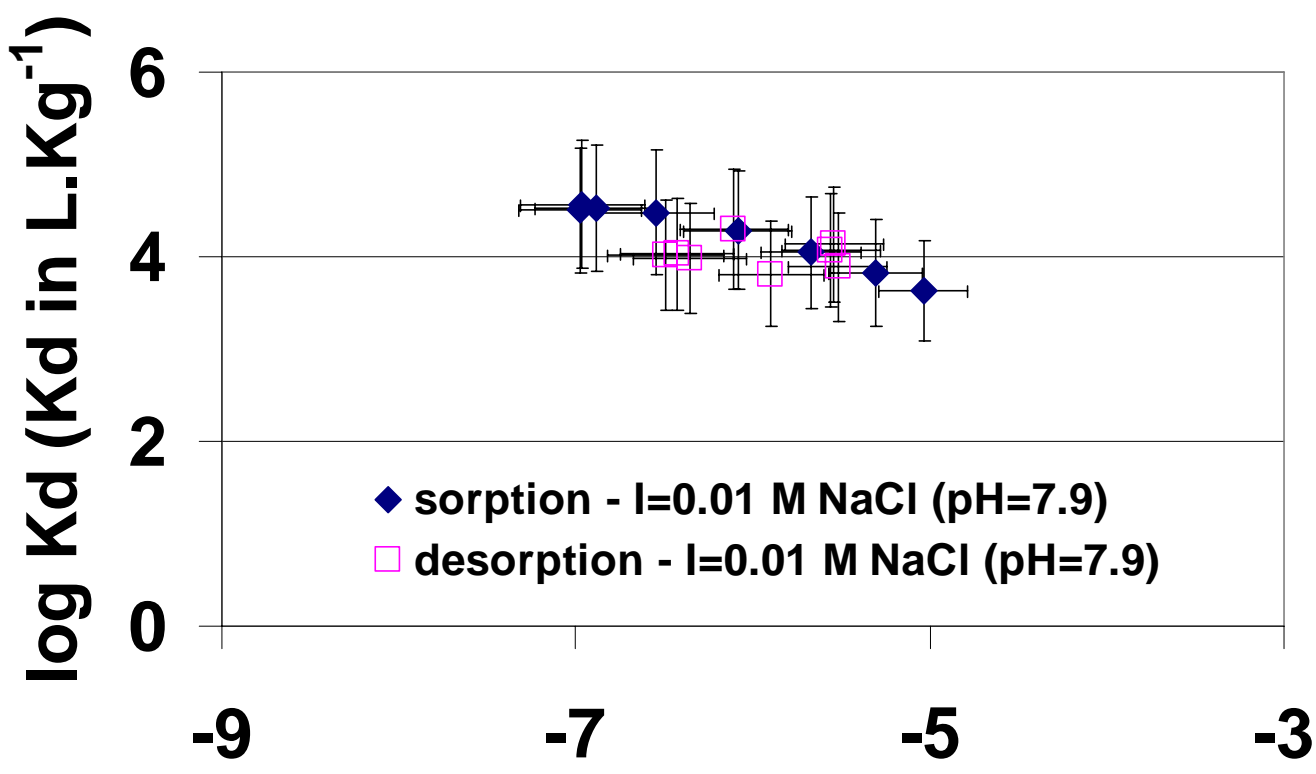

\section{$\log [\mathrm{Zn}(\mathrm{II})]_{\mathrm{aq} \cdot}$ at equilibrium (mol/L)}

Figure 5: Logarithm of the distribution coefficient for zinc sorbed onto Pech Rouge soil as a function of aqueous zinc concentrations in different background solutions. Experimental data obtained at the end of the sorption stage (A). Comparison between data obtained at the end of the sorption and desorption stages (B)

Field of Zn(II) initial concentration is indicated by grey shaded zone on Fig. 5A. 


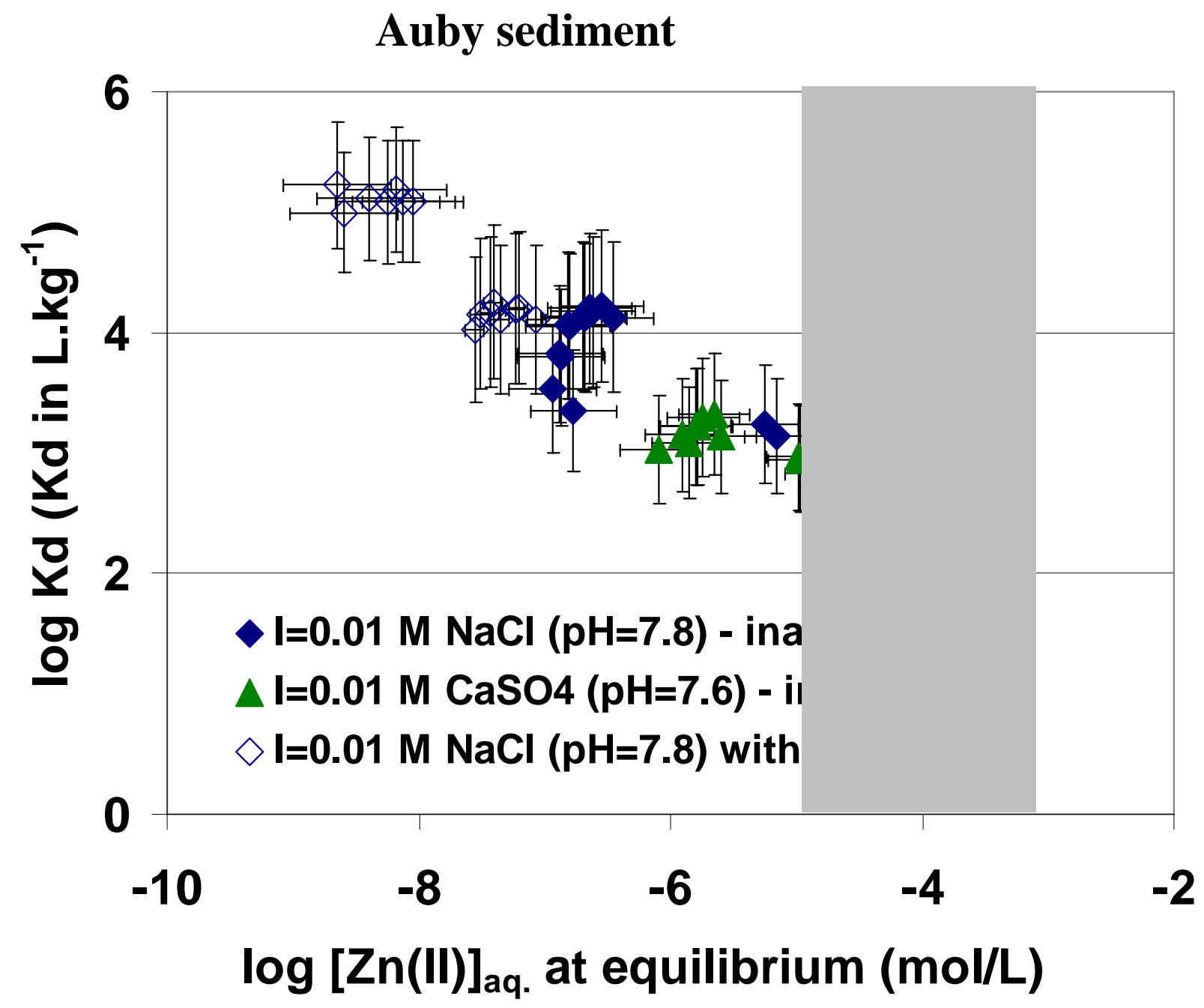

Figure 6: Logarithm of the distribution coefficient for zinc sorbed onto Auby sediment as a function of the aqueous zinc concentrations in different background solutions.

Field of Zn(II) initial concentration is indicated by grey shaded zone. 


\section{A: Pech Rouge soil - \\ $10^{-2} \mathrm{M} \mathrm{NaCl}$ \\ $(\mathrm{pH}=7.9 \pm 0.1)$}

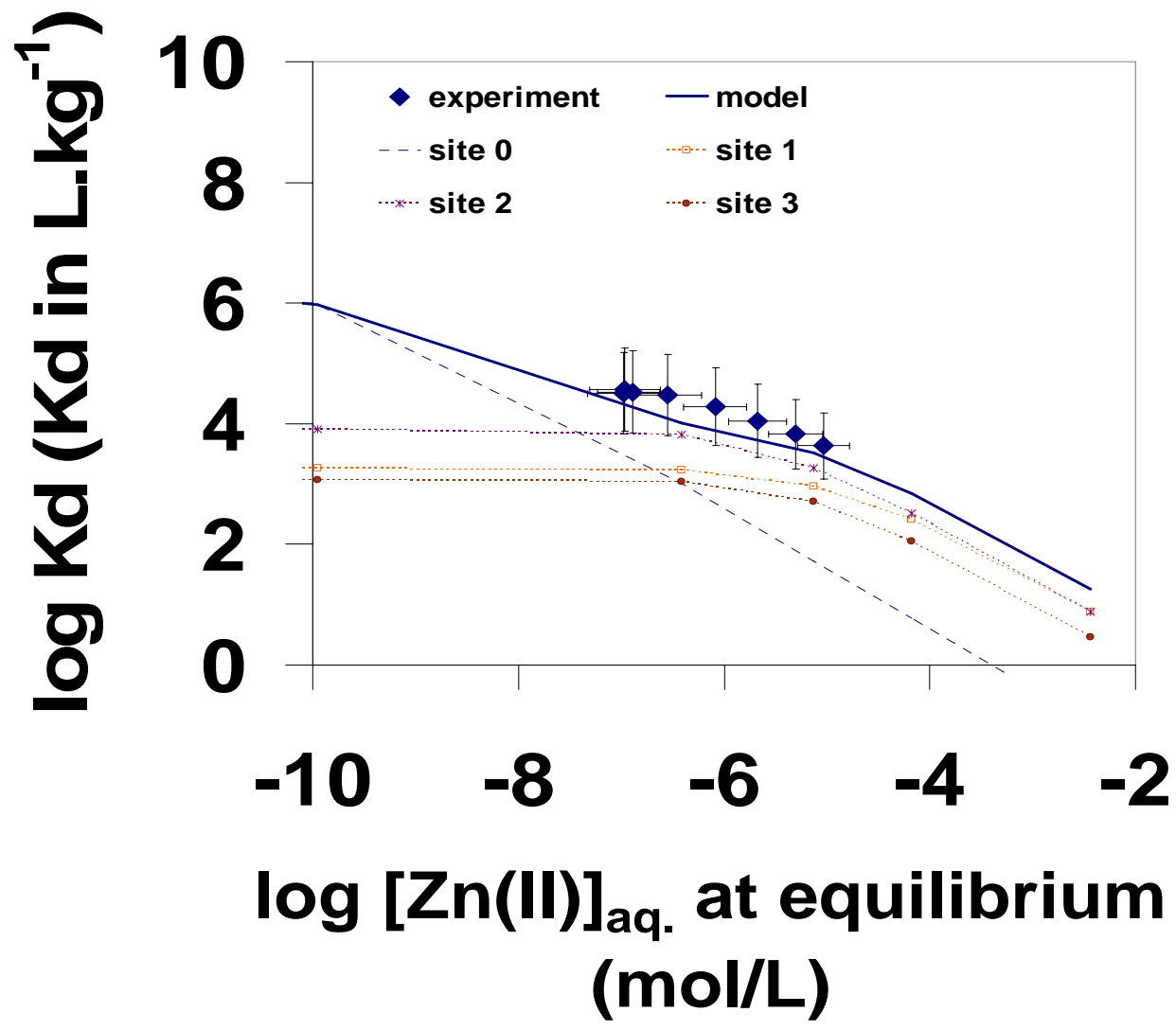

B: Pech Rouge soil -

$0.5 \mathrm{M} \mathrm{NaCl}$ $(\mathrm{pH}=8.5 \pm 0.1)$

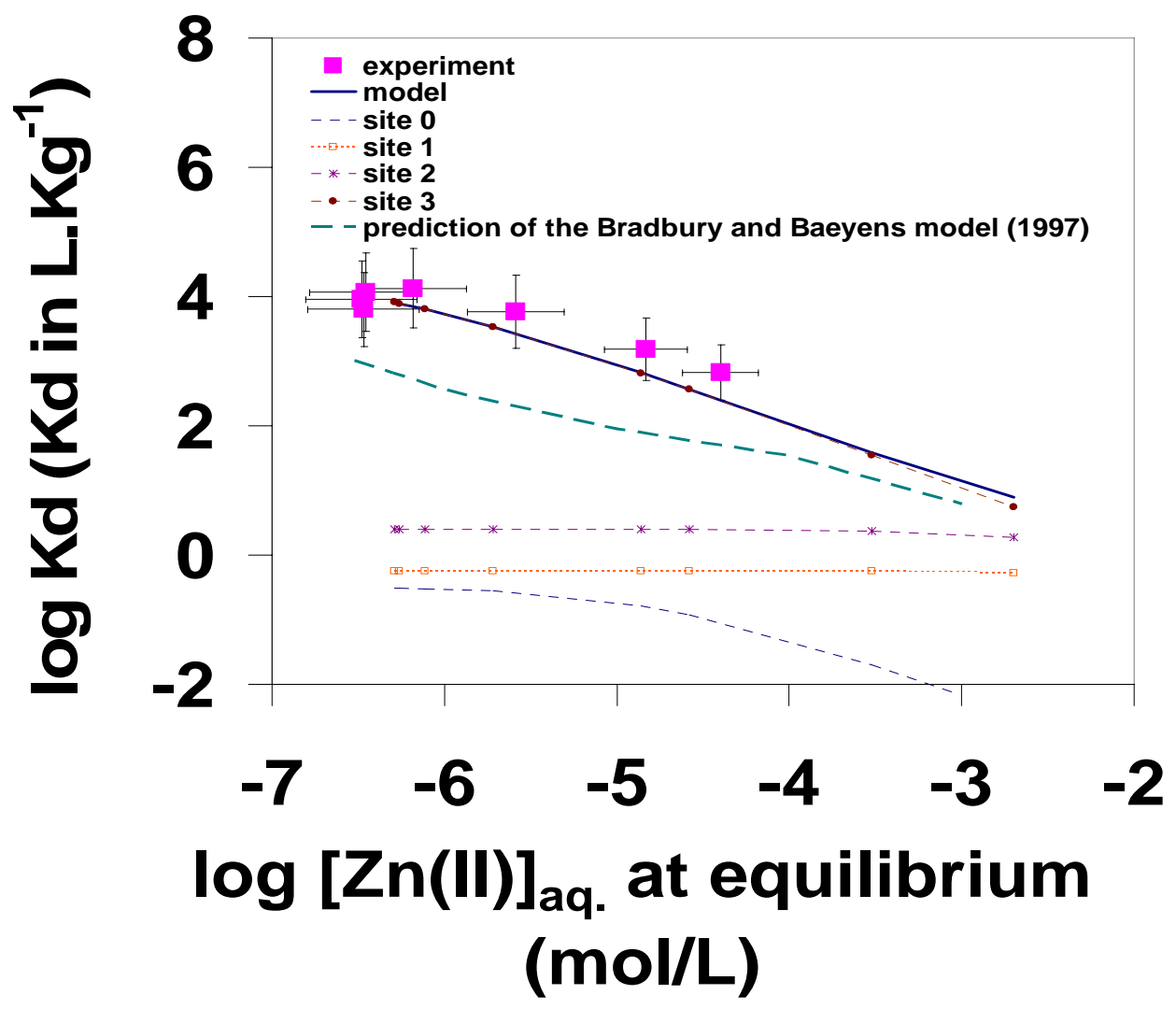

Figure 7: Comparison between measured (symbols) and predicted (continuous lines) Kd data for $\mathrm{Zn}(\mathrm{II})$, as a function of the aqueous zinc concentration. Case of isotherms obtained for the "Pech Rouge" soil in (A) $10^{-2} \mathrm{M} \mathrm{NaCl}(\mathrm{pH}=7.9 \pm 0.1$ ) and (B) $0.5 \mathrm{M} \mathrm{NaCl}(\mathrm{pH}=8.5 \pm 0.1$ ) Both graphs show the contribution of each site to the predicted sorption curve. On Figure $\mathrm{B}$, the prediction of the data by using the Bradbury and Baeyens (1997) model is shown. 


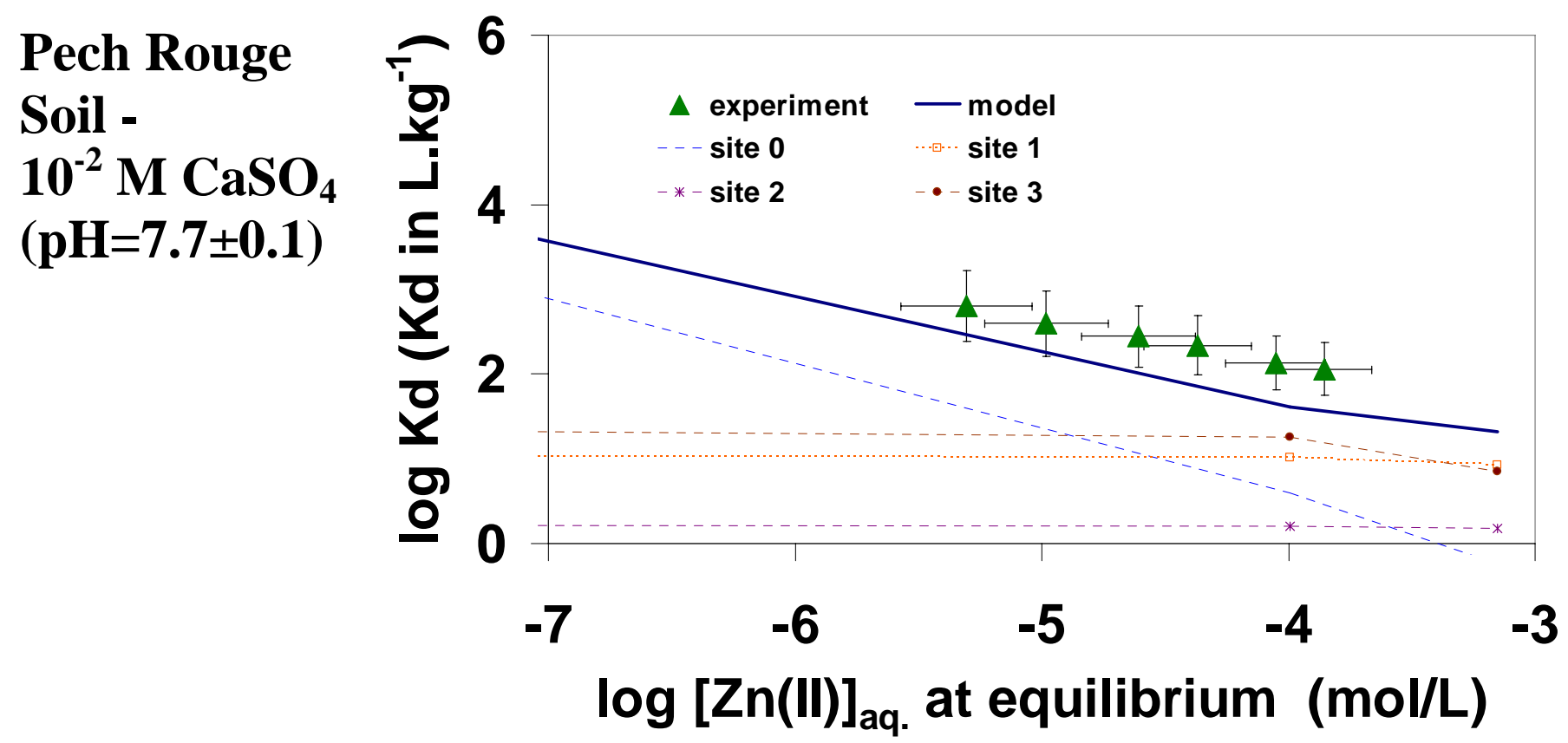

Figure 8: Comparison between measured (symbols) and predicted (continuous lines) Kd data for $\mathrm{Zn}(\mathrm{II})$, as a function of the aqueous zinc concentration. Case of isotherms obtained with the "Pech Rouge" soil in $10^{-2} \mathrm{M} \mathrm{CaSO}_{4}(\mathrm{pH}=7.7 \pm 0.1)$

The graph shows the contribution of each site to the predicted sorption curve. 


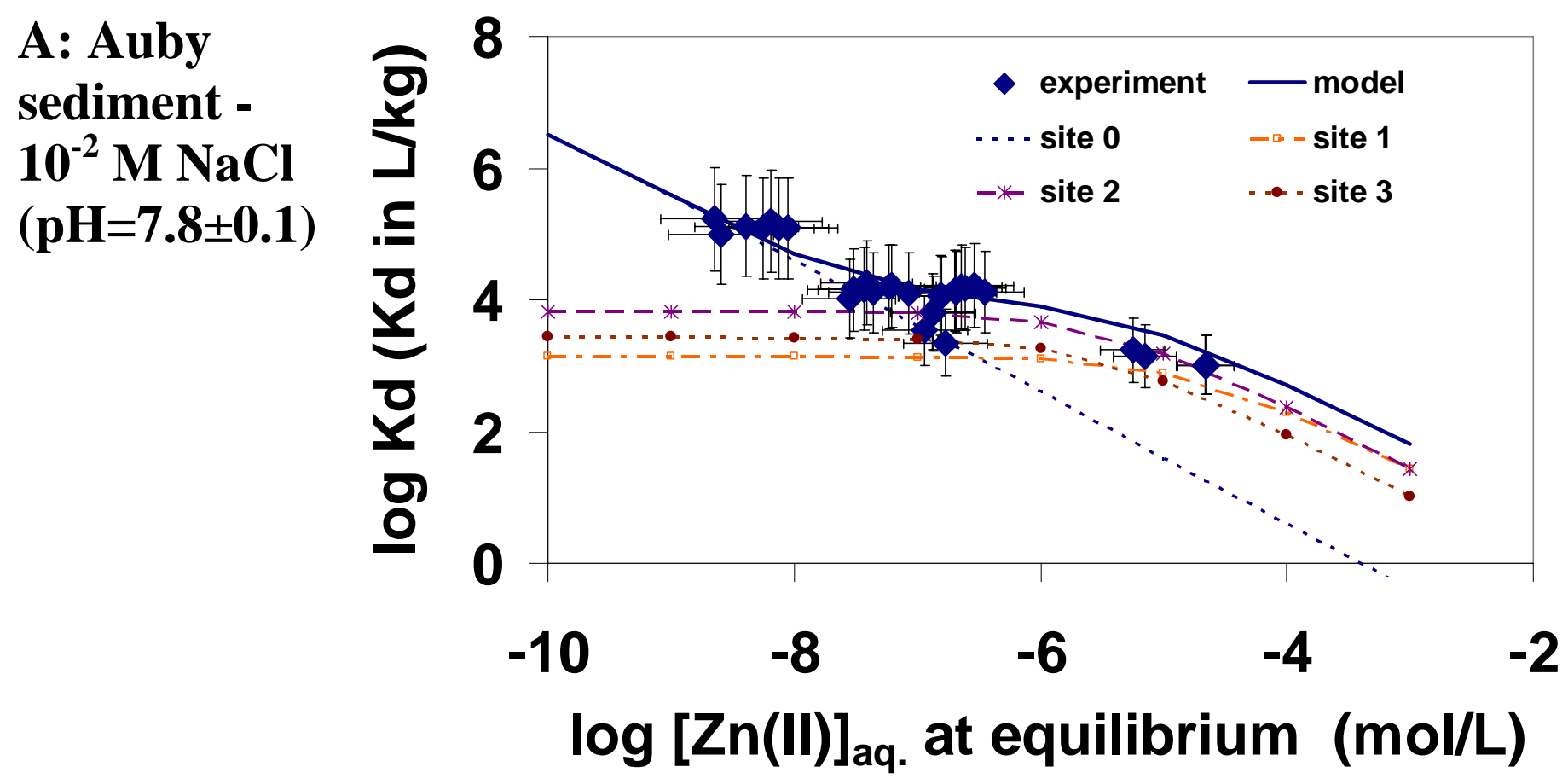

B: Auby

Sediment $10^{-2} \mathrm{M} \mathrm{CaSO}_{4}$

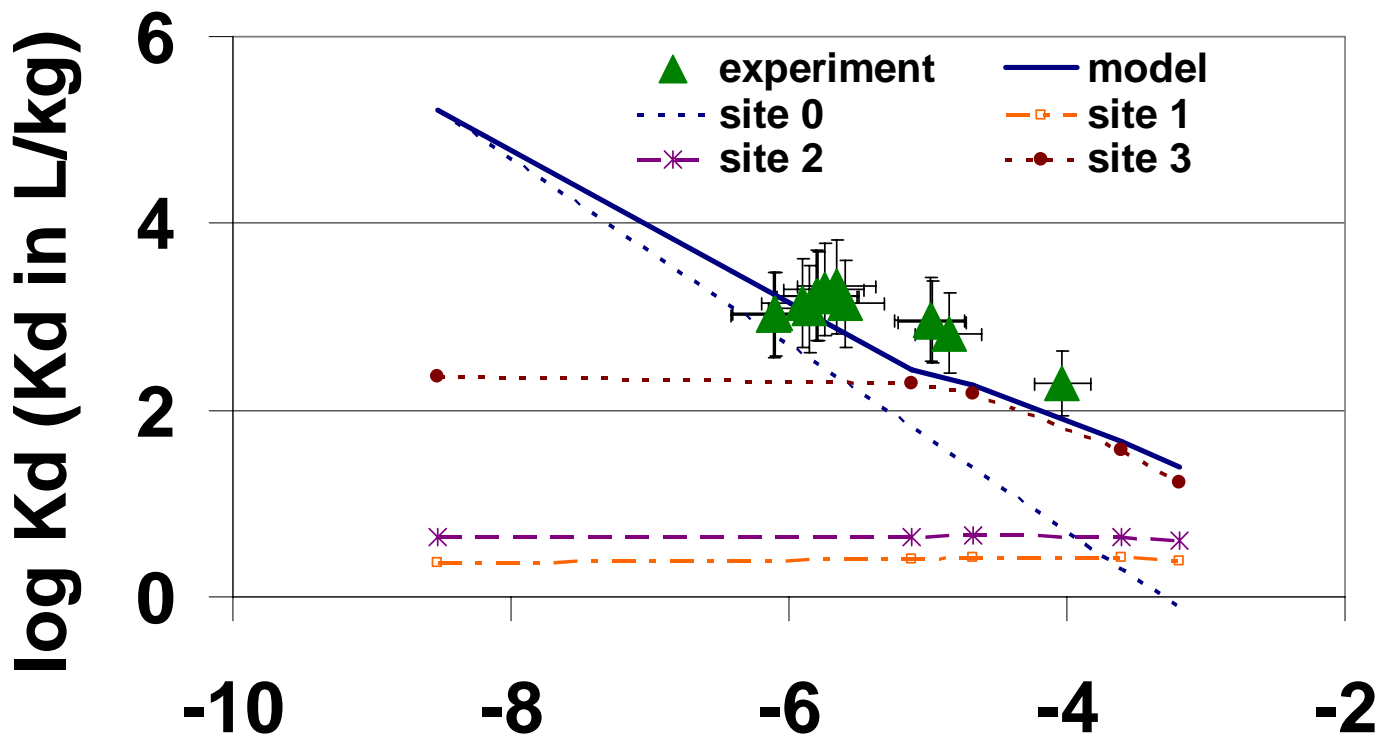

(pH=7.6 \pm 0.1$)$

\section{$\log [\mathrm{Zn}(\mathrm{II})]_{\mathrm{aq} .}$ at equilibrium ( $\mathrm{mol} / \mathrm{L})$}

Figure 9: Comparison between measured (symbols) and predicted (continuous lines) Kd data for $\mathrm{Zn}(\mathrm{II})$, as a function of the aqueous zinc concentration. Case of isotherms obtained with the "Auby" sediment in (A) $10^{-2} \mathrm{M} \mathrm{NaCl}(\mathrm{pH}=7.8 \pm 0.1)$ and (B) $10^{-2} \mathrm{M} \mathrm{CaSO}_{4}(\mathrm{pH}=7.6 \pm 0.1)$. Both graphs show the contribution of each site to the predicted sorption curve. 
Appendix A : Experimental protocol used to determine major sorption sites of a clay mineral (from Gorgeon, 1994; Nolin, 1997; Gaucher, 1998 and Jacquier et al., 2004).

In addition to measuring the total cation exchange capacity of a clay mineral (i.e. CEC), we can discriminate its major sites (i.e. site concentrations $>10^{-3} \mathrm{~mol} / 100 \mathrm{~g}$ ) by modelling the adsorbed concentration of one major cation (i.e. $\mathrm{Na}^{+}$for example) as a function of $\mathrm{pH}$. The experimental curve is also called a "saturation curve", since data are obtained for a homoionic clay (i.e. Na-clay here) under saturated conditions, i.e. with a slight cation excess in solution compared to the quantity sorbed onto the solid.

For $\mathrm{Na}^{+}$sorption, Wyoming Na-montmorillonite suspensions were prepared by dispersing 0.5 $\mathrm{g}$ of this standard clay in $20 \mathrm{~mL}$ of a solution containing $5.10^{-3} \mathrm{~mol} / \mathrm{L} \mathrm{NaCl}$ and $5.10^{-3} \mathrm{~mol} / \mathrm{L}$ $\mathrm{HCl}$. Then, the $\mathrm{pH}$ was adjusted in each tube by adding appropriate amounts of $10^{-2} \mathrm{~mol} / \mathrm{L}$ $\mathrm{NaOH}$ within the $\mathrm{pH}$ range from 3 to 11 . The suspensions were spiked with ${ }^{22} \mathrm{Na}^{+}$, adding 500 $\mu \mathrm{L}$ of a neutral $\mathrm{NaCl}$ solution $\left(5.10^{-3} \mathrm{~mol} / \mathrm{L}\right)$ containing this isotope, and shaken for $24 \mathrm{~h}$. After centrifugation, the supernatants were filtered with $0.22-\mu \mathrm{m}$ pore-size membranes and analysed by capillary electrophoresis (Capillary Ion Analyser, Waters) to obtain $\mathrm{Na}^{+}$aqueous concentration. ${ }^{22} \mathrm{Na}^{+}$aqueous activity was determined by gamma counting (Compugamma, LKB Wallac) and the $\mathrm{pH}$ was measured. The total concentration of adsorbed sodium is given by:

$$
\left[\overline{N a^{+}}\right]=\frac{A_{0}-A}{A} \cdot \frac{V}{m} \cdot\left[N a^{+}\right]_{a q .}
$$

where $\left[\overline{\mathrm{Na}^{+}}\right\rfloor$is the total concentration of adsorbed sodium (mol.g ${ }^{-1}$ of solid), $\left[\mathrm{Na}^{+}\right]_{a q}$ is the aqueous concentration of sodium in the supernatant at equilibrium, $\mathrm{A}_{0}$ is the initial activity of ${ }^{22} \mathrm{Na}^{+}(\mathrm{Bq})$ in solution before sorption, A is the activity of ${ }^{22} \mathrm{Na}^{+}$in the supernatant at equilibrium $(\mathrm{Bq}), \mathrm{V}$ is the volume of the solution and $\mathrm{m}$ the dry weight $\left(60^{\circ} \mathrm{C}\right)$ of the montmorillonite (g).

Concerning sorption of $\mathrm{Na}^{+}$onto Wyoming Na-montmorillonite under saturation conditions, Figure 1 reports experimental data obtained by Nolin (1997) using this method, plotted in terms of adsorbed concentration of sodium versus $\mathrm{pH}\left(\mathrm{I}=0.1 \mathrm{M} \mathrm{NaClO}_{4}\right)$. Then, the data are interpreted by the ion-exchange formalism to obtain both concentrations of major sites and corresponding ion-exchange constants (i.e. $\mathrm{K}_{\mathrm{H} / \mathrm{Na}}$ in this case). 
Appendix B: Thermodynamic constants reported from Pivovarov (2005) and used for calculating the aqueous speciation of zinc. Other constants used for speciation calculations are those of the default Phreeqc $2^{\circledR}$ data base (i.e. SUPCRT92 from Johnson et al., 1992) and are not reported here.

\begin{tabular}{|c|c|}
\hline Equilibrium & $\log \mathrm{K}\left(25^{\circ} \mathrm{C}\right)^{\text {(a) }}$ \\
\hline $\mathrm{Zn}^{2+}+\mathrm{OH}^{-}=\mathrm{ZnOH}^{+}$ & 4.95 \\
\hline $\mathrm{Zn}^{2+}+2 \mathrm{OH}^{-}=\mathrm{Zn}(\mathrm{OH})_{2(\text { aq. })}$ & 9.94 \\
\hline $\mathrm{Zn}^{2+}+3 \mathrm{OH}^{-}=\mathrm{Zn}(\mathrm{OH})_{3}{ }^{-}$ & 13.6 \\
\hline $\mathrm{Zn}^{2+}+\mathrm{Cl}^{-}=\mathrm{ZnCl}^{+}$ & -0.3 \\
\hline $\mathrm{Zn}^{2+}+2 \mathrm{Cl}^{-}=\mathrm{ZnCl}_{2(\text { (aq. })}$ & 0.0 \\
\hline $\mathrm{Zn}^{2+}+\mathrm{HCO}_{3}{ }^{-}=\mathrm{ZnHCO}_{3}{ }^{+}$ & 1.1 \\
\hline $\left.\mathrm{Zn}^{2+}+\mathrm{CO}_{3}{ }^{2-}=\mathrm{ZnCO}{ }_{3(\text { aq. }}\right)$ & 4.7 \\
\hline $\mathrm{Zn}^{2+}+2 \mathrm{CO}_{3}{ }^{2-}=\mathrm{Zn}\left(\mathrm{CO}_{3}\right)_{2}{ }^{2-}$ & 6.9 \\
\hline $\mathrm{Zn}^{2+}+\mathrm{CO}_{3}{ }^{2-}=\mathrm{ZnCO}_{3(\mathrm{~s})}($ smithsonite) & 10.79 \\
\hline $\mathrm{Zn}^{2+}+2 \mathrm{OH}^{-}=\mathrm{Zn}(\mathrm{OH})_{2(\mathrm{~s})}($ ("hydroxyde”) & 16.37 \\
\hline
\end{tabular}

(a) From Pivovarov (2005) 